\title{
Distributive Politics inside the City? The Political Economy of Spain's Plan E
}

\author{
Felipe Carozzi* \\ London School of Economics and Political Science \\ Luca Repetto** \\ Uppsala University
}

\begin{abstract}
We study distributive politics inside cities by analysing how local governments allocate investment projects to voters across neighbourhoods. In particular, we ask whether politicians use investment to target their own supporters. To this aim, we use detailed geo-located investment data from Plan E, a large fiscal stimulus program carried out in Spain in 2009-2011. Our main empirical strategy is based on a close-elections regression-discontinuity design. In contrast to previous studies - which use aggregate data at the district or municipal level - we exploit spatial variation in both investment and voter support within municipalities and find no evidence of supporter targeting. Complementary results indicate that voters may be responding to investment by increasing turnout.
\end{abstract}

Keywords: Political economy; Distributive Politics; Partisan alignment; Local governments.

fEL classification: H70; R53; D72

First Version: December 2016

This Version: February 2019

*Address: Department of Geography and the Environment. London School of Economics. Houghton Street. London WC2A 2AE. Email: F.Carozzi@lse.ac.uk.

**Address: Department of Economics, Uppsala University, Box 513, SE-751 20 Uppsala, Sweden. Email: luca.repetto@nek.uu.se.

We would like to thank the editor, three anonymous referees, Alberto Alesina, Jan Bietenbeck, Marta Curto-Grau, Mikael Elinder, Jon Fiva, Steve Gibbons, Marco Manacorda, Eva Mörk, Daniele Paserman, Rosa Sanchis-Guarner, Alex Solís, and Janne Tukiainen as well as seminar participants at LSE, Uppsala, the MIPP Political Economy Workshop, SAEe 2016, the IEB Workshop on Fiscal Federalism, the European UEA meeting and the Nordic Political Economy Workshop for valuable suggestions and comments. Sebastian Subiabre Vivallos provided excellent research assistance. 


\section{Introduction}

The concern that politicians may divert public resources to specific groups for their own electoral benefit has generated substantial discussion both academically and in the public debate. Voters have been shown to reward incumbents for spending, be it in the form of a specific program targeted to individuals (like an anti-poverty cash transfer, see e.g. Manacorda, Miguel and Vigorito 2011; Pop-Eleches and Pop-Eleches 2012; Baez et al. 2012), or public infrastructure projects (such as a nation-wide road network as in Voigtlaender and Voth 2014). While this literature convincingly shows that voters respond to spending in the polls, it is generally silent on whether and how politicians allocate this spending across voters for electoral purposes.

In this paper we use finely disaggregated data to study whether politicians allocate spending in space in response to the spatial distribution of voters. In particular, we ask if investment spending goes disproportionately to areas of strong support for the incumbent. For this purpose, we use data from Plan E, a large stimulus program that, between 2009 and 2011, endowed Spanish municipalities with 12 billion Euros to fund municipal investment projects, ranging from sport facilities to provision of urban amenities. This program provides an excellent setting to study distributive politics for several reasons. Firstly, municipal governments had substantial discretion in the use of funds with respect to both the type and location of investment projects. Given the urgency to implement this fiscal stimulus, the national government quickly processed the applications for funding, approving in full over $99 \%$ of them (Montolio, 2018). Secondly, the program had a substantial impact on municipal investment. Virtually all municipalities applied, and the amount they received was three times as large as their infrastructures spending in an average year. Finally, Plan E investment projects were geo-located by the municipal authorities. These characteristics of Plan E allow us to exploit within-municipal variation in spending to study distributional politics. ${ }^{1}$

Local governments carry out two-thirds of all public investment in developed countries (OECD, 2013), yet distributive politics studies usually focus on national or, at most, regional level decisions. For this reason, we have an incomplete understanding of whether the welfare distortions that often have been associated with distributive politics (Weingast, Shepsle and Johnsen, 1981) operate at the local level. To our knowledge, we are the first to study the geography of distributive politics inside cities. What enables us to do this is the combination of finely disaggregated data on electoral outcomes and investment projects. ${ }^{2}$ The most important empirical challenge we face when conducting our analysis arises because the geographical distribution of voter preferences is endogenous to economic, social and cultural factors. These factors may, in turn, also affect investment decisions (for example, see Brollo and Nannicini 2012). We overcome this issue by exploiting as-good-as-random variation in the identity of the incumbent party in a close-election regression-discontinuity design. To implement this strategy, we rely on intra-municipal variation in Plan E spending and in the incumbents' electoral support.

\footnotetext{
${ }^{1}$ Throughout the paper, we will sometimes also refer to municipalities as "cities" or "towns".

${ }^{2}$ Our unit of analysis is the census area. Spain has over 35,000 census areas that have no electoral representation and are defined for merely statistical purposes. In 2009 there were a total of 8,114 municipalities in Spain and roughly one in four had more than one census area.
} 
We construct two different measures of party supporter bias at the census area level (our unit of analysis), which will serve as dependent variables in our RDD estimation. A good measure of the extent to which the incumbent targets its supporters should have the following properties. First, it should be large both when a census area with relatively strong incumbent support is favoured disproportionately in the allocation of projects, and when areas of weak support receive little investment. Second, it should indicate a low level of bias in cases of weak support and high investment, or strong support and low investment.

Our RD estimates show that there is no supporter bias in the allocation of projects within municipalities. Specifically, using variation induced by elections won by a small margin, we show that incumbents do not favour areas of strong electoral support. When using our extensive margin measure, point estimates are very small, with our preferred specification yielding a positive and insignificant effect of $1.5 \%$ of a standard deviation of the dependent variable. Estimates using the intensive margin measure, which captures both the amount of investment and the strength of voter support are negative and statistically indistinguishable from zero. Our results stand in contrast to previous studies which use aggregate data at the district or county level and find a positive association between expenditures and incumbent support (Levitt and Snyder, Jr., 1995; Ansolabehere and Snyder, 2006). Furthermore, we note that the partisan bias identified in the alignment literature is entirely absent within cities.

We complement these estimates with an alternative empirical strategy in which we regress different measures of investment on the vote share of the incumbent while including both municipal fixed effects and the vote shares of all major parties as controls. Estimates are in line with those provided using our RD approach. Because we use the full sample, these estimates have the additional advantage of having higher precision.

We explore several possible explanations for our findings. To start, our result could be the consequence of two implicit assumptions in our main empirical analysis: first, that only voters in the census area that receive a project can benefit from it; second, that all different types of Plan E projects have the same effect on voters. We relax these assumptions in two ways. First, we allow investment projects to have spillover effects to neighbouring areas by creating circular buffer areas around each one of them. In this way, a project carried out close to the border of two census areas is counted as having taken place in both. Alternatively, we restrict our sample by concentrating only on those categories of projects that are most likely to have localised benefits. Results from these two additional specifications are in line with our main findings and show that there is no effect of electoral support on investment decisions. On the other hand, we observe that political participation appears to respond to investment: conditional on initial levels, areas that receive a Plan E project experience an increase in turnout. This result has two implications. First, it indicates that projects have a localised effect on voters. Secondly, it suggests that, rather that favouring supporters, politicians may be targeting inactive voters with spending to foster mobilization.

This paper studies the distribution of public money within the city, hence it lies at the intersection between political economy and urban economics. An important strand of this literature asks if political factors can shape local policies. Ferreira and Gyourko (2009) and Pettersson-Lidbom (2008) study how parties differ in implementing policies in the US and Swe- 
den, respectively, using a regression-discontinuity design. Along the same lines, Solé-Ollé and Viladecans-Marsal (2013) show that centre-right municipal governments in Spain have more expansive zoning policies. This literature treats municipalities as units of observation and therefore abstracts from variation within the city boundaries in both the intensity of policy intervention and the geographic distribution of electoral support. Our paper contributes to this literature by investigating partisan differences in policies inside the city.

Our paper also relates to a critique raised by Cox (2009) regarding a frequent mismatch between the theory and the empirics of distributional politics studies. Specifically, while several studies document whether parties target specific districts, they are not informative about how resources are distributed across groups of voters. ${ }^{3}$ Most of these papers analyse the allocation of government funds across municipalities, districts or states (see Wright 1974; Strömberg 2004). ${ }^{4}$ Ansolabehere and Snyder (2006) use data on US state expenditures across counties and find evidence in support of the core voters hypothesis but no evidence of swing voter targeting. By studying allocations across geographical areas within municipalities, our paper avoids the problem highlighted by Cox (2009). Census areas are not districts, counties or municipalities and have no institutional entity of their own, hence can be treated as an aggregation of voters. This allows for a more direct mapping between the predictions of these models and the empirical analysis. Overall, our results show that, when studying allocations within the city, there is little evidence of politicians targeting their supporters. Our setup does not allow us to test whether Plan E funds were used to target swing voters, and that remains an open question.

A growing literature shows evidence of an alignment effect in the allocation of national transfers to local governments. For example, Solé-Ollé and Sorribas-Navarro (2008) and CurtoGrau, Solé-Ollé and Sorribas-Navarro (2018) show that Spanish municipalities aligned with upper tier governments are favoured in the allocation of transfers. Using different research designs, this effect has been documented for several countries, such as Albania (Case, 2001), Italy (Bracco et al., 2015), Portugal (Migueis, 2013), and the United States (Levitt and Snyder, Jr., 1995). We distinguish ourselves from this literature because, in our context, there are no local administrative units or electoral districts between the allocating body and the spatial voter groups that constitute our unit of observation.

\section{Institutional Setting}

\subsection{Plan E}

Plan E was announced in November 2008 in Spain by the PSOE (centre-left) national government of José Luis Rodríguez Zapatero. ${ }^{5}$ It was a large, urgent, stimulus plan aimed at boosting economic activity and fostering employment growth in the midst of the economic crisis. The

\footnotetext{
${ }^{3} \mathrm{~A}$ similar point is made in the review by Golden and Min (2013): "The weakness [of these studies] is that results accord poorly with the individual-level theory that is usually held to be relevant."

${ }^{4}$ An exception, using data on city-level budget allocations is found in Trounstine (2006). This is, however, largely descriptive and does not investigate the spatial distribution of resources within the city.

${ }^{5}$ Formally, the name of the policy was Plan Español para el Estímulo de la Economía y el Empleo (Spanish Plan for Employment and Economic Stimulus).
} 
plan was carried out in two parts, starting in 2009 with FEIL (Fondo Estatal de Inversión Local) - which provided municipalities with roughly 8,000 million Euros - and following with the smaller FEESL (Fondo Estatal para el Empleo y la Sostenibilidad Local) program in 2010 accounting for over 4,000 millions Euros. There was an additional and much smaller plan affecting province-level bodies called $C N$ over this period. In total, Plan E transferred public funds to local government for about $0.8 \%$ of the 2009 Spanish GDP.

The actual investment and spending decisions were carried out by municipalities. Once the project had been approved by the central government, the process followed public procurement rules under the prescriptions of Spanish law. Each municipality was eligible to an amount proportional to its population and had to submit projects to the central government for approval. More than $99 \%$ of municipalities decided to apply. Over $99 \%$ of the submitted projects - each of which could not exceed 5 million Euros - was approved and received full funding (see Montolio 2018 for a thorough discussion of the Plan E timing, with details on the tender and implementation process) ${ }^{6}$

The nearly universal approval rate reflects the fact that criteria to obtain funding were very lax. A subsequent report from the Tribunal de Cuentas (National Audit Office) found that these criteria were generic, imprecise and weakly enforced. This gave local governments ample scope for discretionary use of resources, even allowing several municipalities to use funds for investments that did not fulfil the legal requirements (Tribunal de Cuentas, 2013). ${ }^{7}$ Municipalities had a short window of time to present applications (45 days for FEIL and 90 for FEESL), which essentially consisted of a description of the project and a budget. In order to be eligible for funding, projects had to be new, in the sense that they could not be projects already included in the previous budget, and works had to start within one month of approval.

A total of 57,850 investment projects were carried out by municipal governments using Plan $E$ funding between 2009 and 2011. Table 1 shows the distribution of project categories for the subsample of municipalities that we use in the empirical analysis. The most common projects were related to "rehabilitation and improvement of public spaces", which refers to refurbishment of parks, plazas and pedestrian walkways (see Figure B.9 in the appendix for an example). The second most common type was "equipment and service infrastructure" which is a much more heterogeneous category encompassing street lighting, improvement of transport infrastructure, occasionally refurbishment of parks and sport facilities as well as water works. The average cost of each project was slightly above 210,000 Euros, indicating that small and middlescale projects were common. The Plan E program had a large impact on local government endowments, roughly tripling the pre-crisis amount of yearly resources spent on municipal investment.

Projects had to be clearly advertised by installing a large signboard containing information on the amount spent, the contractor and the expected completion time. The layout, size and content of these signboards was regulated by law. As shown in figure B.10 in the appendix,

\footnotetext{
${ }^{6}$ A total of 19 municipalities did not carry out directly any Plan E project. In all these cases, Plan E funding was allocated to the association of municipalities instead of the municipalities themselves.

${ }^{7}$ The lax criteria of the national government in the approval of projects was motivated by the aim to initiate spending as quickly as possible to attenuate the impact of the crisis.
} 
TABLE 1

Descriptives - Summary of Project Types

Rehabilitation of public space

Basic services infrastructure

Construction and improvement of social and cultural facilities

Cultural and sport related buildings and equipment

Energy efficiency and conservation

Construction and upgrading of education centres

Social buildings and equipment

Urban sustainability and pollution control

Promoting mobility and safety

Protection of historical and landscape heritage

Conservation of historical and municipal sites

Improvement in public spaces and road networks

Other
N. of projects Frequency

5328

20.86

4021

15.74

3697

14.47

2925

2534

1115

1059

729

695

561

396

134

2352
11.45

9.92

4.36

4.15

2.85

2.72

2.2

1.55

.52

9.21

Notes: Number and relative frequency for all the investment projects, by project type. Sample restricted to projects which have correct geocoding information and to the subset of municipalities used in the empirical analysis (see section 3 for details).

signboard's headlines indicated that the project in question was promoted by the municipal government. Given the national coverage received by Plan E, the role of the socialist central government was also quite salient. However, this saliency did not appear to influence project allocations. On the first place, there were no differences between parties in the allocation of Plan E funding per capita. Secondly, it did not lead to local electoral rewards for the Zapatero government. Finally, take-up was generally high and anecdotal evidence suggests that municipal governments were eager to receive the funds regardless of their partisan affiliation. ${ }^{8}$ This is also supported by the fact that the types of projects carried out by PSOE mayors and other mayors are, on average, very similar. We will return to these possible issues in detail in section 5.

As table 1 shows, most of the public works executed with Plan E financing are likely to have geographically localised effects, therefore benefiting voters who live close to the site of the project. Anecdotal evidence indicates that local politicians are aware of this. ${ }^{9}$ This notion motivates our use of the census area, a small area within the municipality, as unit of analysis. When discussing our results in section 4, we will relax the assumption that the benefits of a project accrue only within the census area.

\footnotetext{
${ }^{8}$ A centre-right politician from Partido Popular we interviewed said: "It was an enormous grant, which many interpreted as a letter to the three kings" (our translation), referring to the biblical Magi bringing gifts to the newborn Jesus.

${ }^{9}$ An interviewed local official responsible for urban planning declared that projects were assigned "[...] so that they had high visibility in the neighbourhood". A prominent politician from Madrid, referring to the beneficiaries of investment projects, added "evidently, carrying out a project entails benefits for the neighbours in the area." (our translation).
} 


\subsection{Municipalities and Local Elections}

Spain had 8,114 municipalities in 2009. Municipalities are the lowest level of territorial administration of the Spanish state and have autonomy in managing their interests as recognized in the Spanish constitution. Their functions are partly dependent on size and encompass lighting, transport network upkeep, public parks, local services (e.g. sports facilities, public libraries), waste disposal, water and sewage services. ${ }^{10}$ Municipal financing is based on municipal taxes (the largest of which are a property tax and a tax on firms) and transfers from the national and regional governments. Note that Plan E project financing was not part of these regular transfers.

Spanish municipalities are small, in the sense that functional urban areas or commuting zones encompass several municipalities at once. Hence, we can think of each municipality as encompassing one or less that one labour market, with very little to no spatial segmentation of labour markets within municipalities. This is relevant insofar as we expect the employment effects of Plan $E$ to move labour demand across all the municipality and not only in targeted neighbourhoods.

The governing body is the municipal council and its members are directly elected by residents. Municipal elections are held every four years under a single-district, closed list, proportional electoral system. ${ }^{11}$ The single-district electoral rule is important for our analysis as it allows us to treat spatial units within the municipalities as voter groups rather than electoral districts. It also grounds the notion that all votes for a party contribute the same towards the goal of winning government (something that does not apply in multi-district constituencies).

Municipal council seats are assigned following the D'Hondt rule. The average size of councils elected under the closed list system is roughly 10 , with the number of members ranging from 7 in the smaller towns up to a maximum of 57 in Madrid. The municipal mayor is elected by the council under a majority rule and in general this majority is obtained through coalition building after elections. The council votes proposals by the mayor, who acts mainly as an the agenda-setter. Given the strong discipline enforced by parties in Spain and the impossibility of calling early elections, local governments are usually stable. Below, the ruling party refers to the party of the mayor.

For data collection and voting purposes, the National Statistical Institute (INE) divides the Spanish territory into roughly 35,000 census areas (also referred to as electoral areas) with no administrative powers. These areas are defined as a function of municipal boundaries and population. Census areas are the smallest spatial unit for which we can obtain electoral results from Ministry of Internal Affairs (Ministerio del Interior). Given that many municipalities are small, only 2,278 of them had more than one census area within their boundaries in 2007 .

\footnotetext{
${ }^{10}$ See details in law number 7/1985 (2 of April 1985, Ley Reguladora de las Bases del Régimen Local).

${ }^{11}$ See Chapter IV of Ley Orgánica del Régimen Electoral General. Municipalities with populations under 250 inhabitants have an open list system with voters able to express multiple preferences for different candidates. These municipalities will not be used in our analysis.
} 


\subsection{Political Parties in 2007 and 2011}

The socialist party (PSOE) held the national government between 2004 and 2011 under two terms of President Zapatero. At the national level, the centre-right Popular Party $(P P)$ was the main opposition party and eventually took power from the socialists in 2011.

The municipal elections before and after Plan E took place in 2007 and 2011, respectively. In the 2007 election, the two main parties, Zapatero's $P S O E$ and the centre-right $P P$, obtained comparable results. A total of $36 \%$ of all municipalities were ruled by PSOE in 2007, while $39 \%$ were ruled by $P P$. In 2011, almost three years into the financial crisis, these figures changed to $27.6 \%$ and $46.5 \%$ respectively. In both terms, the third party with most appointed mayors was the nationalist Catalan party Convergència $i$ Unió which ruled $5.2 \%$ and $6.3 \%$ of municipalities, respectively. In total, the 9 most important national level parties in Spain ruled $89 \%$ of municipalities in 2007 and $87 \%$ of them in $2011 .{ }^{12}$ A number of smaller, local parties, rule the remaining municipalities.

\section{Data and Descriptive Statistics}

In order to study how the geography of voter support shapes public spending allocations we need disaggregated data on electoral outcomes and geo-located data on Plan E investment projects. Data on individual projects were obtained directly from the Plan E website, and include the coordinates of projects (as geo-located by the municipal authorities), a short description, a classification in terms of project types and the cost of each project.

The raw data contain a total of 57,850 projects. Some categories correspond to investments that clearly yield no differential geographical benefit to voters. For example, spending on technological upgrading of the public administration is usually geo-located in the city hall but its benefits go beyond people living next to the city hall. We identify and exclude a total of 6,574 projects which correspond to these categories. ${ }^{13}$ In addition, for a subset of projects, the geolocation data on latitude and longitude is incorrect or missing. When possible, we geo-located these projects manually using address or other location information from the short project description. In total, we were able to hand code 3,065 projects ourselves. Our final sample therefore contains a total of 38,353 projects (for details on these restrictions see table B.2 in the appendix). Project types in this sample and their frequencies are displayed in table 1.

We combine information on Plan E investment projects with data on municipal and national elections. Data on electoral outcomes at the census area level are obtained from the Ministry of Internal Affairs, the body responsible for collecting and disseminating information on electoral results. We complement it with information on mayors and their political party of affiliation

\footnotetext{
${ }^{12}$ These are PP, PSOE, CIU, IU, CC, ERC, PNV, PAR and BNG. By national level parties we mean parties that also run in national elections.

${ }^{13}$ The categories in question are: technological upgrading of the public administration, electronic management, industrial rehabilitation, efficiency in the management of water sources, management and treatment of urban waste, repairs in water supply systems and repairs in sewage outlet systems. These types of projects are unlikely to give any localized benefits to voters, as they are either specific to the municipal administration process, or are related to water and sewage networks. Regarding industrial promotion projects, much of the related benefits would affect the local labour market as a whole. The excluded categories amount to less that $8 \%$ of all Plan E costs.
} 


\section{FIGURE 1}

Plan E Projects and political support for PSOE (red) ANd PP (blue)
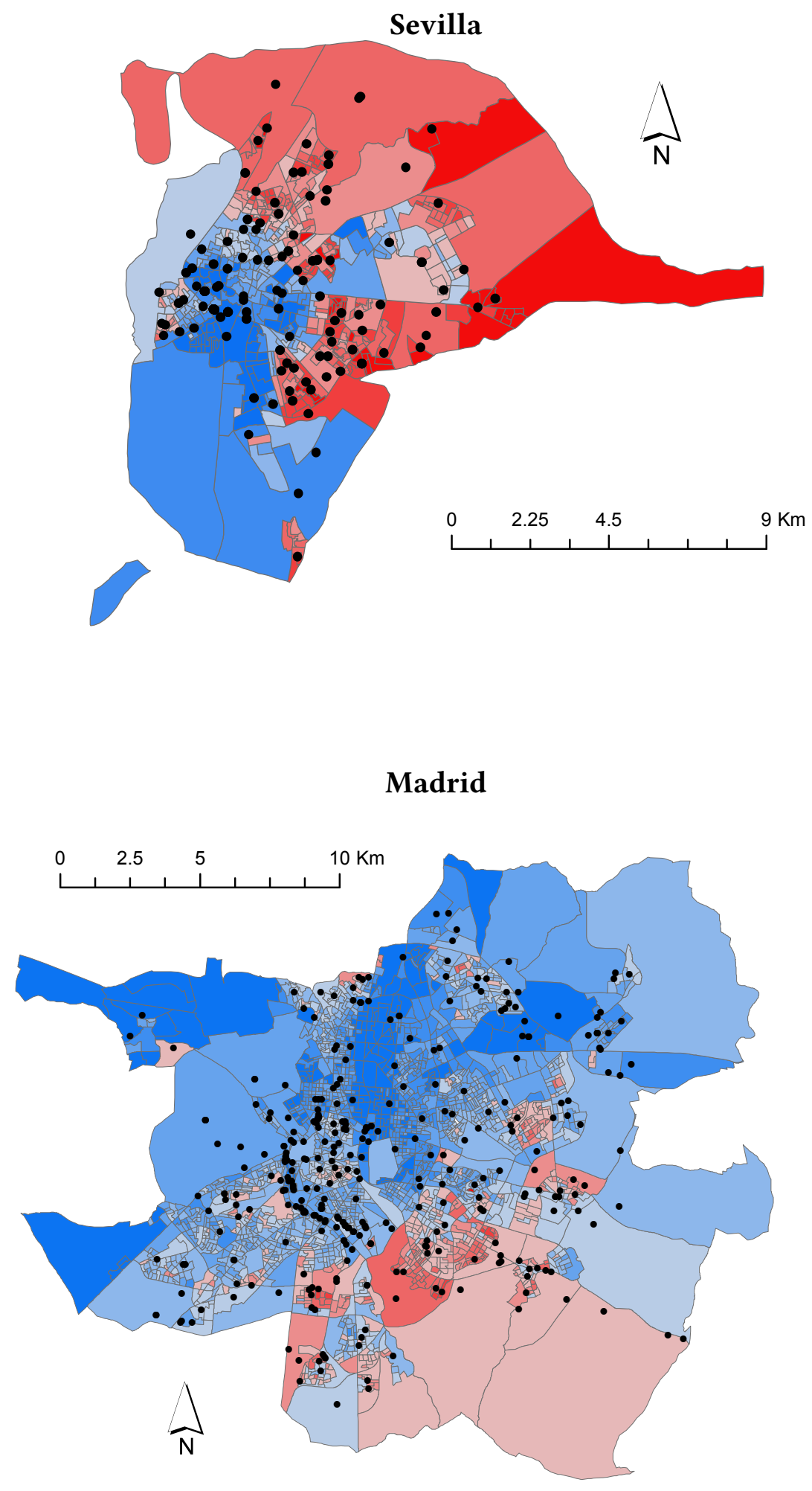

Notes: Points correspond to Plan E projects located in the municipalities of Sevilla (top panel) and Madrid (bottom panel). Census areas are coloured in red if the socialist party PSOE received the majority of votes in the 2007 municipal election, with the intensity of the shade varying with the vote share. Similarly, blue areas correspond to areas where the right-wing $P P$ obtained the majority of votes. 
from the same source. Figure 1 plots results of the 2007 municipal elections for each of the census areas of Sevilla and Madrid, together with the distribution of Plan E projects. Red areas are those where left-wing PSOE was the most voted party while blue indicates areas of PP majority. We can see that the support for both parties varies significantly across neighbourhoods. This within-city variation in electoral support will be instrumental to study the link between the geography of voter support and the allocation of Plan E projects in the following sections.

Finally, we integrate our dataset with municipal and census area level information from INE (the national statistical office) and from the 2001 Population Census. Census data includes characteristics at the census areas level such as population and density, together with the fractions of college graduates, unemployed, home-owners, foreigners, the number of children, and elderly residents. To control for possible factors affecting the local demand for investment, we also use information on the number of households that reported the presence of crime and a lack of green areas in the neighbourhood. Lastly, we also include the fraction of urban discontinuous terrain at the census area level (obtained from Corine Land Cover).

We limit our analysis to municipalities having at least two census areas. This is essential in order to have variation in vote shares within each municipality. By doing so, we exclude small towns, restricting our sample to 2,278 municipalities. We will further restrict our analysis to municipalities ruled in 2007 by one of the 9 national level parties with most mayors. We impose this restriction in order to ensure we can correctly match the party names in the census area electoral data with those appearing in the data on mayors. Our final sample is composed of 2,046 municipalities which include a total of 28,083 census areas.

Table 2 includes some descriptive statistics for the census areas in our sample. As Panel A shows, the average census area has a surface area of about 8 squared kilometres, and 1,400 inhabitants, of which 1,100 are eligible to vote. Given that these areas are designed to contain comparable numbers of voters, there is substantial variation in their physical size, matching the variation in densities, from large cities with small census areas to sparsely populated and extended countryside villages with large ones. Panel B indicates that $40 \%$ of census areas received at least one Plan E project, with a corresponding average investment per capita of 215 Euros. Finally, the last panel of table 2 shows some average figures from the 2001 Population Census variables that will be used as controls in our main specification. Descriptives at the municipal level are reported in table B.1 in the appendix.

\section{Empirical Analysis}

In this section we test whether incumbent local politicians target their own supporters in the allocation of Plan E investment projects. To understand our empirical strategy, consider the following thought experiment. There are several cities, each ruled by either party A or party B. Each city is composed of neighbourhoods, which can support party A or B. We define a local government as favouring its supporters if it disproportionately allocates investment to its neighbourhoods, neglecting neighbourhoods of the opposing party.

If parties are not assigned randomly, observing that certain areas are favoured may be the result of inherent differences between cities beyond the identity of the ruling party. For example, suppose cities ruled by party A are more likely to have parks and that party A supporters 


\begin{tabular}{lcccc}
\hline & Mean & Std. dev. & Min & Max \\
A. General information & & & & \\
Surface $(2007, \mathrm{~km}$ ) & 8.41 & 34.69 & 0.004 & 1125.112 \\
Density $(2007,1000$ inh./km2) & 19.86 & 21.55 & 0.001 & 349.804 \\
Population (2007) & 1,423 & 563.75 & 294 & 12,859 \\
Eligible voters (2007) & 1,100 & 441.03 & 226 & 10,881 \\
Turnout (2007) & 0.61 & 0.12 & 0.085 & 0.922 \\
Turnout (2011) & 0.62 & 0.10 & 0.157 & 1.000 \\
B. Plan E projects & & & & \\
Indicator for receiving 1+ projects & 0.40 & 0.49 & 0.00 & 1.00 \\
N. of projects received & 0.91 & 1.72 & 0.00 & 49.00 \\
Investment in projects (Euros per capita) & 214.76 & 713.16 & 0.00 & 33420.26 \\
C. Population Census information (2001) & & & & \\
Higher education & 0.12 & 0.10 & 0.000 & 0.556 \\
Home owners & 0.84 & 0.12 & 0.004 & 1.000 \\
Foreigners & 0.04 & 0.05 & 0.000 & 0.811 \\
Households with 1+ unemployed & 0.16 & 0.07 & 0.003 & 0.730 \\
Households reporting not enough green areas & 0.38 & 0.24 & 0.000 & 0.993 \\
Households reporting crime is high & 0.24 & 0.19 & 0.000 & 0.977 \\
People 0-16 yrs. & 0.15 & 0.05 & 0.031 & 0.394 \\
People 16-64 yrs. & 0.67 & 0.05 & 0.280 & 0.927 \\
People 65+ yrs. & 0.17 & 0.08 & 0.006 & 0.654 \\
& & & & \\
Observations & & 28,083 & & \\
\hline
\end{tabular}

Notes: Panel A reports averages for some characteristics of interest for the 28,083 census areas in the sample (2,046 municipalities). Turnout figures refer to the 2007 and 2011 municipal elections, respectively. Panel B shows descriptives for the Plan E investment program, and panel C shows data from the 2001 Population Census. These variables measure, for a given census area, the fraction of people with a particular characteristic at the time of the Census. In some categories - explicitly indicated - the unit of observation is the household and not the individual.

prefer to live close to parks. If parks need recurring investments, we would observe a spending bias towards party A neighbourhoods even if these local governments had no intention to favour their supporters. The randomisation of the party in office would instead guarantee that all municipal characteristics are balanced. In this case, a comparison of the allocations between municipalities would be free of the bias induced by omitted variables correlated with the location of voters. This comparison could then be used to detect the presence of supporter bias. $^{14}$

Let us translate this thought experiment into our context. In the first place, our "neighbourhoods" will be census areas and we will use previous votes shares at the census area level

\footnotetext{
${ }^{14}$ In principle, it is possible that mayors favour their neighbourhoods not to reward their voters, but simply in accordance with their preferences. For instance, socialist mayors might favour socialist areas not because they want to favour their supporters, but because their residents are poorer than average. Just like in other studies on distributive politics, one needs to take this caveat into account when interpreting the estimates.
} 
as a measure of support for different parties within cities. Secondly, the assignment of Plan E projects in space will be used to determine which census areas receive more resources. Finally, we exploit quasi-random variation in the identity of the ruling party by implementing a closeelection regression-discontinuity design (or RDD, see, e.g., Lee 2008). For this purpose, we need to select a reference party and measure to what extent areas supporting this party are favoured in the allocation of resources when this party wins an election by a narrow margin. We select the center-left $P S O E$ as our reference party because this was the party with most mayors in our 2007 sample. $^{15}$

To implement a regression-discontinuity design, we need to define both a running variable and a census-area level variable measuring whether PSOE voters are favoured in the allocation of investment. Regarding the former, the standard used in the literature is the margin of victory of the reference party (e.g., Lee 2008; Beland 2015). This would be appropriate in the context of direct election of mayors. However, in a multi-party system with indirect election of mayors, the margin of victory is not an appropriate measure of closeness of an election. Instead, we adapt Fiva, Folke and Sørensen (2018)'s procedure (which draws on the insights by Folke 2014) and construct our running variable by computing the vote share distance to a PSOE seats majority in the local council. To measure favouritism towards PSOE voters, we construct two different measures combining information on Plan E investments and the PSOE vote share. These will be designed to capture both intensive and extensive margins in allocations and voter preferences. We turn to these issues in the following. In the final part of this section, we also consider an alternative estimation method that does not rely on close elections and yields similar results.

\subsection{Close-Elections Regression-Discontinuity Design}

The first step to implement our RD strategy is to construct a running variable that measures the closeness of the municipal election. Given the electoral system prevailing in Spain, we follow the method described in Fiva, Folke and Sørensen (2018) as subsequently adapted by Curto-Grau, Solé-Ollé and Sorribas-Navarro (2018) to the Spanish setting. As an illustration of the procedure, assume that, after the election, PSOE obtained the majority of seats in a given municipality. ${ }^{16}$ The running variable is constructed using an iterative procedure as follows. First, we reduce the vote share of PSOE by a small amount (in our case, we used $0.25 \%$ ), and redistribute the corresponding votes among the other parties, proportionally to their initial vote shares. Then, we calculate the new distribution of seats using the D'Hondt rule. If the seats majority did not change, we decrease the vote share by an additional $0.25 \%$, iterating the procedure until a change in the majority is reached. The change in the vote share needed to reach a majority change is the value of our running variable for the municipality in question, henceforth simply the PSOE winning margin. In this particular example, the winning margin is positive because PSOE started with a seat majority. In municipalities where PSOE did not

\footnotetext{
${ }^{15}$ Note that the choice of the reference party is somewhat arbitrary and should only have a minor effect in estimation. In a two party system, this choice is without loss of generality as the estimated effects are obtained from differences between the two parties (for example, in US studies such as Beland 2015, the reference party is usually the Democratic party). Unreported estimates using right-wing $P P$ as the reference party yield similar results.

${ }^{16}$ We say PSOE has a majority when it has strictly more seats than any other party in the municipal council.
} 
have a majority to start with, we proceed in the opposite way, adding votes until a majority is reached. In these cases the winning margin variable is negative. We perform these calculations for all municipalities in our sample.

Figure 2 shows that, as expected, the winning margin ranges from -0.5 to 0.5 . Furthermore, it does not appear to jump discontinuously around zero, suggesting that there is no systematic manipulation around the threshold where the seats majority change. The absence of a discontinuity in the distribution of the running variable is evidence in support of one of the fundamental RDD assumptions, namely that parties are unable to perfectly manipulate electoral outcomes (Lee, 2008; McCrary, 2008). A formal McCrary test for the absence of a discontinuity yields a p-value of 0.16. Using Cattaneo, Jansson and Ma (2016)'s RD manipulation test, however, we fail to reject the null with a p-value of 0.51 . Both provide formal grounding to the assumption of absence of manipulation at the threshold.

\section{FIGURE 2}

\section{HISTOGRAM OF THE DENSITY OF THE WINNING MARGIN VARIABLE}

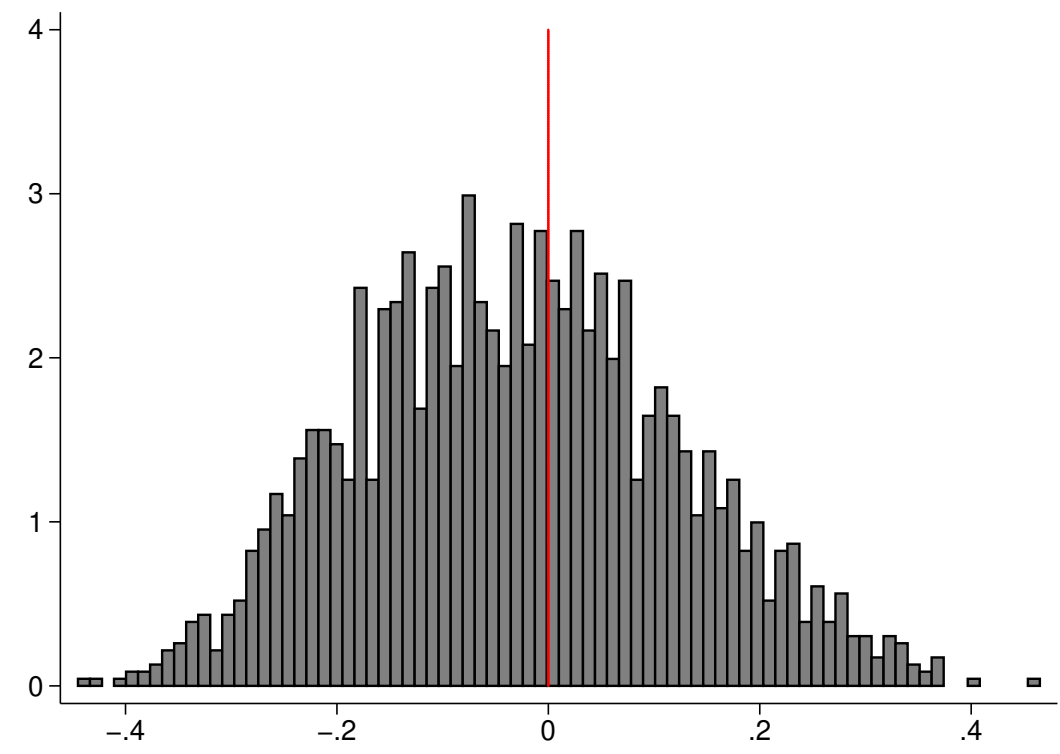

Notes: Histogram of municipal level PSOE winning margin for all municipalities in the sample, defined as the PSOE vote share change necessary for PSOE to win the seat majority in the municipal council (details in the text). Positive values correspond to municipalities in which PSOE obtained the majority of seats in the 2007 elections. Negative values correspond to municipalities in which PSOE did not obtain the majority in 2007. Test of no perfect manipulation as in McCrary (2008) leads to a p-value of 0.16. Alternatively, the test proposed in Cattaneo, Jansson and Ma (2016) yields a p-value of 0.51 .

Because of the indirect election of mayors in Spain, obtaining the majority of seats does not necessarily lead to mayoralty. Therefore we need to implement a fuzzy RDD, in which the indicator for a PSOE mayor is instrumented by an indicator for the winning margin being positive (Imbens and Lemieux, 2008). The corresponding first stage is as follows:

$$
P S O E_{m}=\pi_{0}+\pi_{1} \mathbf{1}(\text { PSOE WinMargin } m>0)+f\left(P S O E \text { WinMargin }_{m}\right)+\gamma_{0}^{\prime} X_{c m}+u_{c m},
$$


where $P S O E_{m}$ is a dummy taking value 1 if $P S O E$ is in power in municipality $m$ by the time Plan E was carried out, WinMarginPSOE $E_{m}>0$ is a dummy taking value 1 if PSOE obtained the majority of seats in the 2007 municipal elections and $f\left(P S O E\right.$ WinMargin $\left._{m}\right)$ is a polynomial in the winning margin. $X_{c m}$ is a vector of census-area level controls including the logarithm of population, census area density and surface, the fraction of urban discontinuous terrain, the distance from the municipal centroid, and a set of control variables from the 2001 Census. ${ }^{17}$ We will report estimates of two types. First, we use the full sample controlling for third degree global polynomials in the running variable. Second, we apply the optimal bandwidth selector by Calonico, Cattaneo and Titiunik (2014) (henceforth CCT) to restrict the sample to observations close to the threshold, and use linear control functions in the forcing variable on either side. Given that local linear regression estimators have more attractive properties for discontinuity estimates, this is our preferred specification (Gelman and Imbens, 2014). In all specifications in this section, we weight each observation by the inverse of the number of census areas so that each municipality has the same weight. ${ }^{18}$ Figure 3 shows that the probability of a PSOE government jumps discontinuously around the winning margin threshold. First-stage regressions using different bandwidths are provided in table B.3 in the appendix and confirm our instrument is strong, with F-statistics above 30 in all cases.

\section{Figure 3}

\section{First Stage Discontinuity}

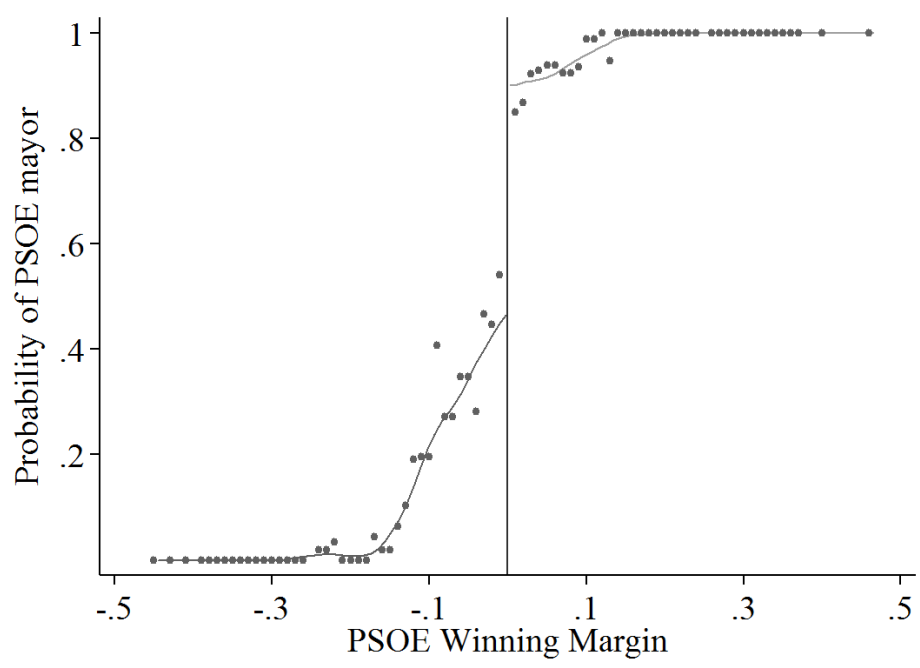

Notes: The vertical axis measures the probability of having a PSOE mayor and horizontal axis measures the winning margin of PSOE in the 2007 municipal elections, as defined in the text. Positive values indicate the municipality had a PSOE seat majority and negative values indicate it did not. Solid lines represent fitted values from a local polynomial smooth regression estimated with an Epanechnikov kernel and bandwidth calculated using Silverman's rule-of-thumb.

\footnotetext{
${ }^{17}$ Specifically, the fraction of individuals who are unemployed, foreign-born, college-educated, aged 0-16, aged 16-64; the fraction of households reporting crime is an issue, lack of green areas, or owning a home.

${ }^{18}$ In practice the weighting is implemented using the inverse of the number of census areas as "analytical weights" in STATA 14, the software used in estimation. The rdbwselect command that calculates the Calonico, Cattaneo and Titiunik (2014) optimal bandwidth also allows for weights. Weighting observations by the ratio of the population in the census area and the municipal population yields very similar results.
} 
Before moving on to the definition of the dependent variable, we present some evidence in favour of the continuity assumption required for the validity of RDD in figure 4 . This figure shows the averages for several census area characteristics calculated in bins of $1 \%$ of the winning margin, together with fitted values from a local linear regression. ${ }^{19}$ On average, the observed discontinuities at the threshold are relatively small in magnitude, with only surface and homeownership rates exhibiting a jump of around a third of a standard deviation. These results suggest that municipalities where PSOE barely won the elections are comparable, in terms of observables characteristics, to those where PSOE barely lost. Table 3 shows discontinuity estimates for each covariate using our main specification, which uses a local linear regression allowing for a different slope at either side of the threshold. The bandwidth is calculated using the CCT method on our main specification (of equation 2 below) and is equal to $9.6 \%$. Regression results are consistent with the graphical evidence, and only one of the estimates is statistically significant at the $10 \%$ level.

\section{TABLE 3}

REGRESSION RESULTS FOR THE BALANCE OF COVARIATES

\begin{tabular}{lcccccc}
\hline & Population & Surface & Density & Crime & Unemployed & No green \\
\hline PSOE majority & 0.135 & -0.069 & $0.086^{*}$ & 0.068 & 0.115 & -0.076 \\
& $(0.110)$ & $(0.165)$ & $(0.051)$ & $(0.068)$ & $(0.156)$ & $(0.105)$ \\
\hline$R^{2}$ & 0.00 & 0.00 & 0.01 & 0.01 & 0.00 & 0.00 \\
Observations & 13314 & 13315 & 13314 & 13315 & 13315 & 13315 \\
& & & & & & \\
& Homeowners & Foreigners & College ed. & Aged 0-16 & Aged 16-64 & Aged 65+ \\
\hline PSOE majority & -0.110 & -0.053 & 0.037 & -0.047 & 0.151 & -0.080 \\
& $(0.080)$ & $(0.115)$ & $(0.052)$ & $(0.089)$ & $(0.113)$ & $(0.108)$ \\
\hline$R^{2}$ & 0.00 & 0.01 & 0.01 & 0.00 & 0.01 & 0.00 \\
Observations & 13315 & 13315 & 13315 & 13315 & 13315 & 13315
\end{tabular}

Notes: Census-area level regressions. Coefficients are the estimated jumps in each covariate at the threshold of winning margin equal to zero, using a local linear regression with bandwidth equal to $9.6 \%$ at each side, chosen applying the Calonico, Cattaneo and Titiunik (2014) method on equation 2 using the extensive bias measure. Population is in logarithms. All variables are measured at the census area level and standardized to have zero mean and unit variance. Each observation is weighted by the inverse of the number of census areas in the municipality. Results using different bandwidths are analogous. S.e. are heteroskedasticity-robust.

To implement the RD design, we need to construct a measure of "supporter bias" at the census area level. Given that our analysis is at the census area level but the RDD provides exogenous variation in the "treatment" (the identity of the mayor) only at the municipal level, we need this measure to have certain properties. First, it should be large when a census area with relatively strong PSOE support is favoured disproportionately in the allocation of projects (and, conversely, when areas of weak support receive low investment). Second, it should indicate a low level of bias in cases of weak support and high investment (and, conversely, strong support and low investment). A variable with these properties would pick up the disproportionate

\footnotetext{
${ }^{19}$ Variables are standardized to have zero mean and unit variance for ease of interpretation.
} 


\section{FIGURE 4}

\section{BALANCE OF COVARIATES CHECKS}
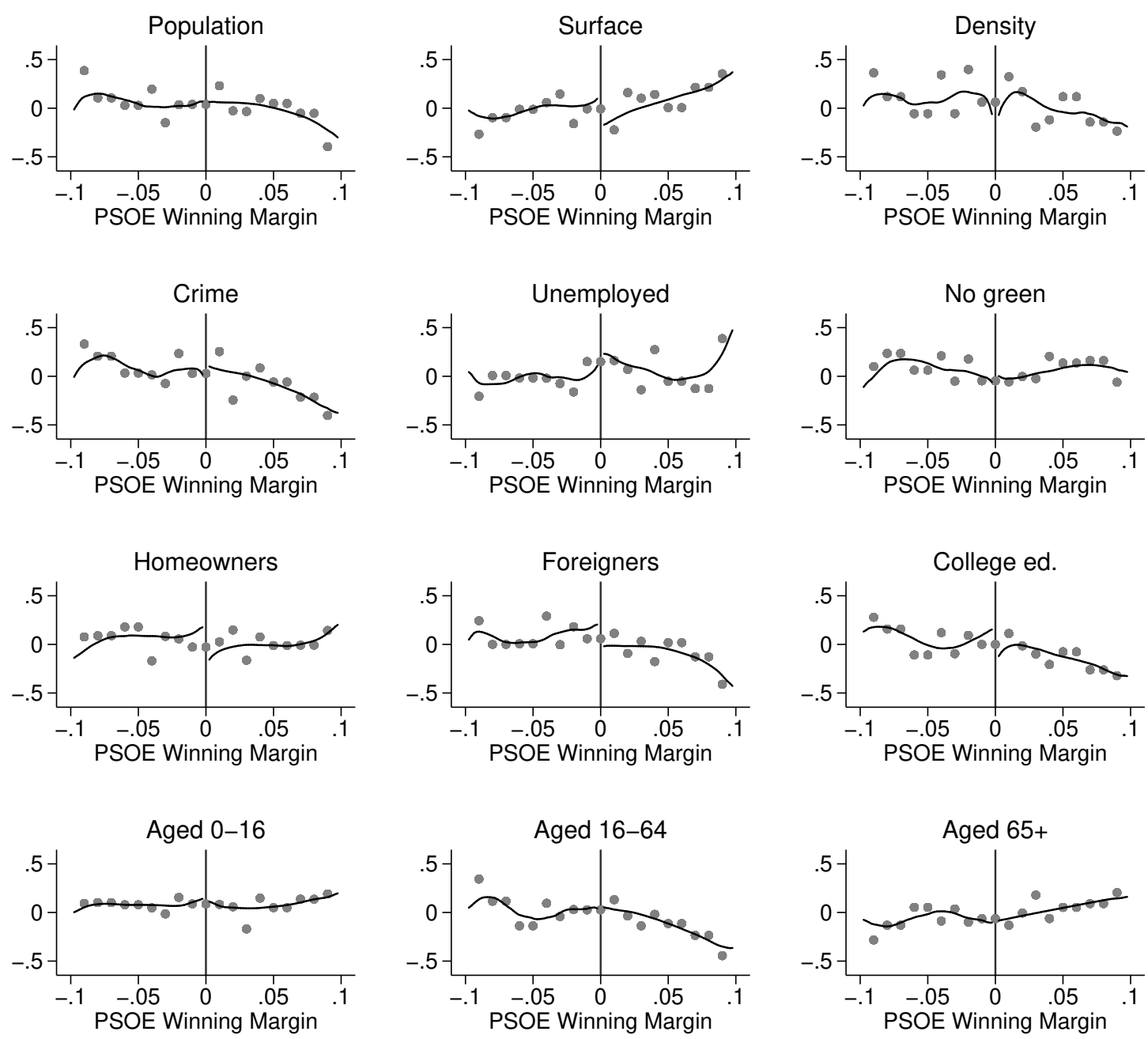

Notes: Balancing checks for each covariate used in the RDD estimation. Population, surface, and density are in logarithms. All variables are municipal averages across census areas and standardized to have zero mean and unit variance. Dots are averages within intervals of $1 \%$ of the winning margin. Solid lines represent fitted values from a local linear regression estimated with an Epanechnikov kernel and bandwidth calculated using Silverman's rule-of-thumb.

allocation of projects to (or away from) PSOE areas.

We consider two alternatives. The first measure is meant to capture the extensive margin of investment, that is, the discrete decision of whether to invest or not in areas with many supporters. This measure, which we denote as ExtensiveBias ${ }_{\mathrm{cm}}$, is defined as the interaction of a variable that equals one if census area $c$ in municipality $m$ received at least one Plan $E$ project (and -1 otherwise) and a variable that equals one if the PSOE vote share in this area is higher that the $P S O E$ vote share in the municipality (and -1 otherwise). Using a negative number instead of the zero in the definition of these two indicator variables allows the resulting bias measure to be symmetric, being positive when a supporter bias exists and negative when it does not. Applying this definition to our data we find that $52 \%$ of census areas have a value of -1 and the remaining $48 \%$ of areas have a value of 1 . 
Because it is the interaction of two binary variables, ExtensiveBias $\mathrm{cm}_{\mathrm{cm}}$ can only capture the extensive margin of supporter bias. It does not respond to differences in the amount of investment received by different areas or in the strength of electoral support. To incorporate intensive margin variation, we construct another measure of supporter bias, IntensiveBias $\mathrm{cm}_{\mathrm{cm}}$, as the interaction of the difference between the Plan E investment (in per capita terms) carried out in the census area and the municipal average investment, and the difference between the PSOE vote shares at the census area level and the municipal aggregate vote share. This variable is able to capture, at the same time, differences in the intensity of investment and in the presence of more or less supporters across census areas. Hence, it is a more suitable variable to test our main hypothesis. Its histogram - provided in Figure 5 - shows substantial heterogeneity across census areas.

\section{Figure 5}

\section{Histogram of the Intensive Margin Measure of Supporter Bias}

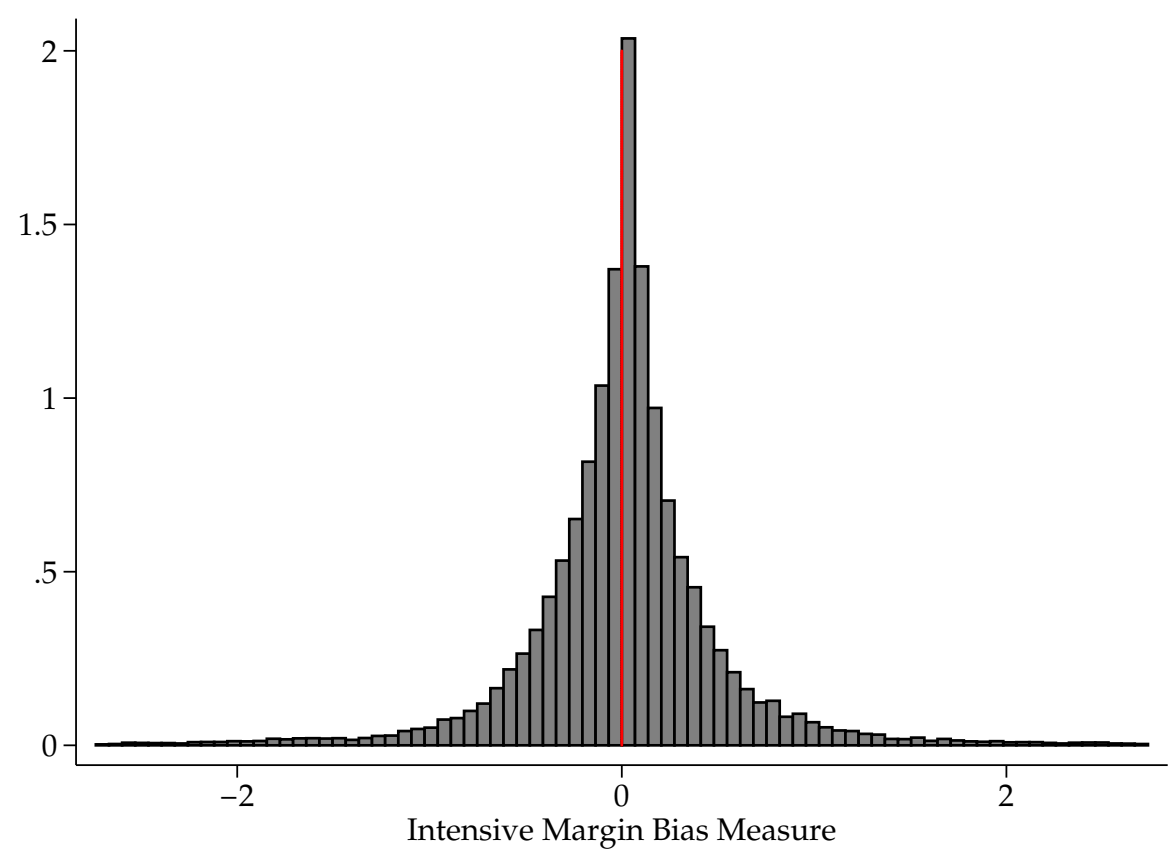

Notes: Histogram of our intensive margin measure of bias toward PSOE supporters (details in the text). Our variable is represented in the horizontal axis and has been normalized to have a mean of 0 and standard deviation equal to 1 . The lowest and highest percentiles of the distribution are not displayed.

We can clarify the interpretation of our variables with a simple example. Suppose a municipality with 5,000 inhabitants is divided into two census areas, A and B, with equal populations. During the previous elections, PSOE obtained a 59\% vote share in area A and $47 \%$ in area B. Now suppose that Plan E is rolled out and the municipality in question implements one project in area A. In this case, our extensive margin measure takes value 1 , as this census area received a project and had PSOE vote share above the municipal average. Moreover, the value of our extensive bias measure will also be 1 for $\mathrm{B}$ because this census area did not receive a project and had a PSOE vote share below the municipal average. The bias measure is 1 for all areas in the municipality because this municipal allocation does exhibit PSOE voter bias.

Let us now turn to our continuous bias measure, assuming the project cost 100,000 Euros. 
Hence, Plan E spending per capita is 0 in section B (which received no project), 40 in A, and 20 on average. Our intensive bias measure is computed combining these figures with vote share deviations from the municipal average. In census area A, PSOE obtained a vote share of 6 points above the municipal average, so its intensive bias measure will be given by $(40-20) \times(59-$ $53)=120$. In the case of section B, this figure will be $(0-20) \times(47-53)=120$ too. Again, the allocations and vote shares in both sections are consistent with favouring of PSOE voters. It is straightforward to see that, if we moved our hypothetical Plan E project from section A to section B, both measures will change sign. Note also that the measures for A and B are identical in this simplified example but will in general be different.

Using our bias measures, we specify the structural equation that completes our fuzzy-RD model as

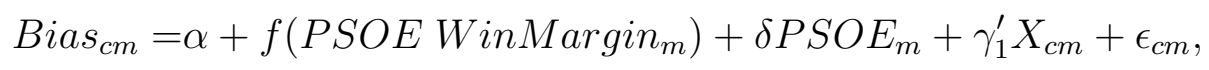

where, as above, $c$ indexes census areas and $m$ indexes municipalities. The outcome variable Bias $_{c m}$ can be either ExtensiveBias ${ }_{c m}$ or IntensiveBias ${ }_{c m}$, vector $X_{c m}$ include controls as defined above, and $P S O E_{m}$ is an indicator for PSOE being in charge of the municipal government. To have scale-free measures of bias and facilitate the interpretation of our results, we standardize both Bias $_{c m}$ using their overall mean and standard deviation. ${ }^{20}$

As usual in regression-discontinuity studies of this kind, estimates are obtained using local variation coming from close elections. Hence, the group of municipalities that we use for identification are electorally competitive by construction. Therefore, our RD results can be interpreted as measuring supporter targeting in competitive electoral contexts. If supporter targeting were a specific feature of electorally uncompetitive environments (as suggested, for example, in Trounstine 2006), then it might be problematic to extrapolate our local result to the rest of the population.

The running variable measures the distance to or from a PSOE that is seat majority. Therefore, at the threshold, both the identity of the party with most seats and PSOE's seat share jump. Our interpretation of the $\mathrm{RD}$ estimates requires assuming the exclusion restriction holds, that is, changes of PSOE's seat share at the threshold do not directly affect the propensity of a local government (whether it is PSOE or another party) to allocate Plan E resources to areas populated with socialist voters. Conditioning on PSOE's seat share or on the seat share of the most voted party does not change our main results, which suggests this assumption is plausible. ${ }^{21}$ For transparency, in the following section, together with the fuzzy-RD results, we will show reduced-form estimates, which do not rely on the validity of the exclusion restriction. Then, in section 4.3, we provide an alternative estimation strategy that avoids some of these issues.

Two final points are due regarding the role of ideology. First, the supporter bias estimated using $\mathrm{RD}$ could pick up parties' preferences rather than tactical redistribution to supporters.

\footnotetext{
${ }^{20}$ Note that it is possible that both of our bias measures contain measurement error. However, measurement error in the dependent variable will not lead to a bias in coefficients as long as this error is uncorrelated with the regressors.

${ }^{21}$ Results are not reported for brevity but are available upon request.
} 
Second, given our choice of reference party, one may be concerned that our results are only informative about PSOE mayors. However, using $P P$, the party with the second-highest number of mayors in the period, yields the same results (which we omit for brevity).

\subsection{Estimation Results}

Before moving to a formal estimation of the RD model, in figure 6 we show how our two bias measures behave as a function of the PSOE winning margin, with dots representing weighted averages in bins of size $1 \%$ and lines being local linear regression estimates. Because both measures are standardized, the effect at the discontinuity can be interpreted in terms of standard deviations of the dependent variable. The graphical evidence indicates that the reduced-form effect of a PSOE mayor on both supporter bias measures is modest, and well below one-tenth of a standard deviation.

Fuzzy RD estimates of equation 2 are reported in table 4 for both the extensive and intensive margin measures and including or excluding controls. In the first two columns, we use the whole sample and include in estimation a third-degree polynomial in the winning margin, while in the last two we restrict the sample to observations within the Calonico, Cattaneo and Titiunik (2014) optimal bandwidth, using a linear control function.

Our estimates show that PSOE mayors who won the election by a small margin do not favour areas where relatively more of their supporters live. We interpret this as evidence against our hypothesis. When using the extensive margin measure, point estimates are very small, with the largest suggesting a positive effect of $4.9 \%$ of a standard deviation. When using the optimal bandwidth, the magnitude decreases to $1.5 \%$ with a corresponding $95 \%$ confidence interval of $[-0.29,0.32]$. While the clustered standard errors are relatively large, the confidence intervals allow us to rule out effects larger that one-third of a standard deviation in either direction. In column 5 we report reduced-form estimates of the effect of PSOE having the majority of seats on our measure of bias. These estimates do not rely on the exclusion restriction that PSOE seat majority has a direct effect on supporter bias other than its direct effect on the likelihood of electing a PSOE mayor. Hence, they provide a measure of the combined effect of PSOE winning the majority of seats and having the mayor.

Panel B shows similar estimates using the intensive margin measure, which captures continuous variation in the amount of investment and the strength of voter support. Taking as a reference the specification with controls and optimal bandwidth of column 4, again we observe a small (in this case negative) effect, with a 95\% confidence interval of $[-0.30,0.07]$, again confirming that PSOE does not appear to significantly target its voters with the allocation of investment projects. Even if estimates are larger in absolute value than those obtained using the intensive bias measure, they are more precise, probably owing to the fact that we also exploit variation in the size of investment and electoral support. Reduced-form point estimates are slightly smaller in absolute value. For the extensive bias measure, crossing the threshold results in a statistically insignificant effect of $0.5 \%$ of a standard deviation. We then conclude that switching to a PSOE seat majority has no effect on the allocation of resources to areas with relatively more $P S O E$ voters.

In the rightmost panels of figure 6, we explore the sensitivity of our $\mathrm{RD}$ estimates to different bandwidth choices by estimating the model restricting the sample to smaller and smaller 
Figure 6

REDUCED-Form PLOT AND FUZZY-RDD ESTIMATES OF SUPPORTER BiAS
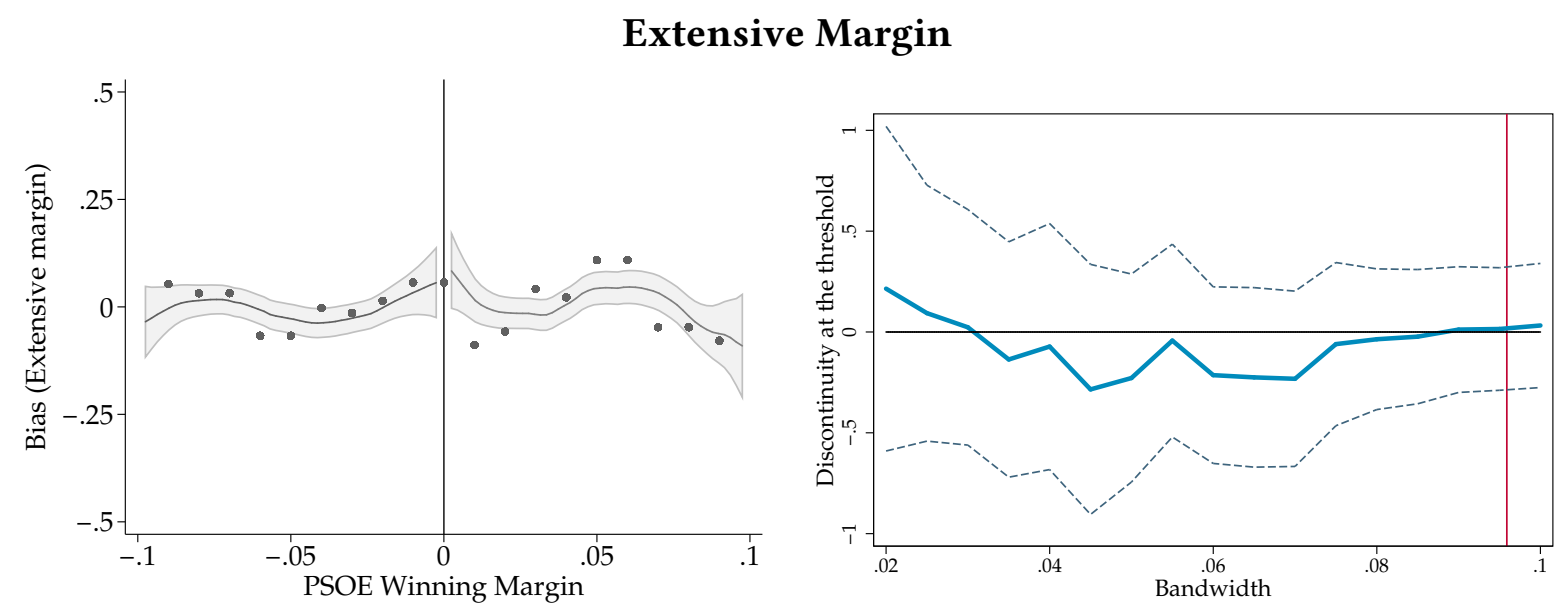

\section{Intensive Margin}
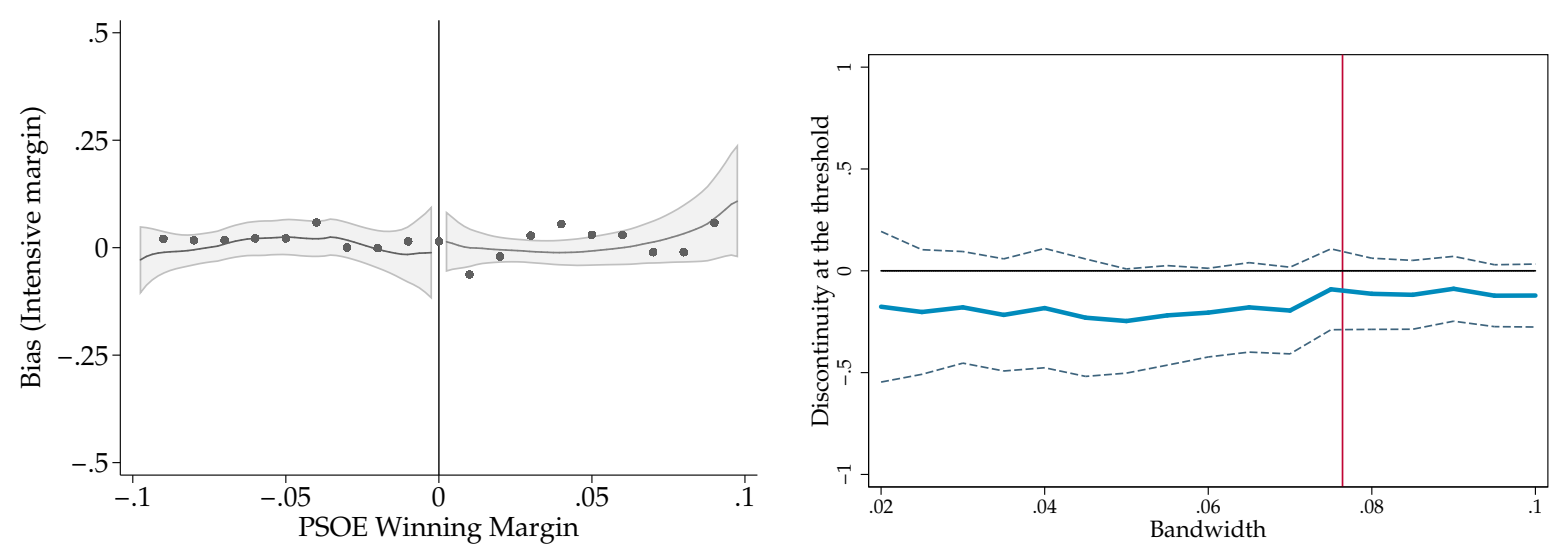

Notes: Left panels: The vertical axis shows the intensive and extensive measures of bias in the allocation of Plan E projects towards PSOE voters. The horizontal axis shows the PSOE winning margin, defined as the vote share distance to a seat majority change. Dots are averages in $1 \%$ intervals of the winning margin, with each observation being weighted by the inverse of the number of census area in the municipality, so that all municipalities have the same weight. The lines are local linear regression estimates using the Epanechnikov kernel and a bandwidth calculated using Silverman's rule-of-thumb. All variables are standardized. Right panels: RDD results from equation 2 for the extensive and intensive margin measures of PSOE supporter bias. Both outcome variables are normalized to have zero mean and standard deviation equal to one. The solid lines report point estimates using different bandwidth values as specified in the horizontal axis. 95\% confidence intervals based on clustered s.e. displayed as dashed lines. Vertical lines correspond to Calonico, Cattaneo and Titiunik (2014) optimal bandwidths.

bandwidths in increments of $1 \%$ of the winning margin. The CCT optimal bandwidth is reported for reference as a vertical line. As the graphs show, point estimates are small for most magnitudes and smaller than 1/10 of a standard deviation at the CCT bandwidth for either measure. As we narrow down the bandwidth around the majority threshold, the estimates become less precise - as shown by the widening of confidence intervals - but remain statistically insignificant. Given that the increase in the standard errors is due to the sample size reduction and that point estimates oscillate tightly around zero without a clear pattern, we infer that our 
TABLE 4

RDD Results - Supporter Bias in Allocation of Investment

\begin{tabular}{|c|c|c|c|c|c|}
\hline & \multicolumn{2}{|c|}{ Full sample } & \multicolumn{2}{|c|}{ CCT bandwidth } & \multirow[t]{2}{*}{ Reduced form } \\
\hline \multicolumn{5}{|c|}{ A. Extensive Margin Measure } & \\
\hline PSOE mayor & $\begin{array}{c}0.046 \\
(0.197)\end{array}$ & $\begin{array}{c}0.049 \\
(0.200)\end{array}$ & $\begin{array}{c}0.032 \\
(0.151)\end{array}$ & $\begin{array}{c}0.015 \\
(0.155)\end{array}$ & \\
\hline PSOE seats majority & & & & & $\begin{array}{c}0.005 \\
(0.057)\end{array}$ \\
\hline Bandwidth & 0.500 & 0.500 & 0.096 & 0.096 & 0.096 \\
\hline Controls & $\mathrm{N}$ & $\mathrm{Y}$ & $\mathrm{N}$ & $\mathrm{Y}$ & $\mathrm{Y}$ \\
\hline Obs. & 27897 & 27885 & 13246 & 13245 & 13245 \\
\hline \multicolumn{6}{|c|}{ B. Intensive Margin Measure } \\
\hline PSOE mayor & $\begin{array}{l}-0.108 \\
(0.098)\end{array}$ & $\begin{array}{l}-0.117 \\
(0.100)\end{array}$ & $\begin{array}{l}-0.112 \\
(0.091)\end{array}$ & $\begin{array}{l}-0.116 \\
(0.093)\end{array}$ & \\
\hline PSOE seats majority & & & & & $\begin{array}{l}-0.040 \\
(0.032)\end{array}$ \\
\hline Bandwidth & 0.500 & 0.500 & 0.076 & 0.076 & 0.076 \\
\hline Controls & $\mathrm{N}$ & $\mathrm{Y}$ & $\mathrm{N}$ & $\mathrm{Y}$ & $\mathrm{Y}$ \\
\hline Obs. & 27527 & 27517 & 10816 & 10816 & 10816 \\
\hline
\end{tabular}

Notes: Columns 1-4: RDD results for the extensive and intensive margin measures of PSOE supporter bias. Column 5 shows the corresponding reduced-form estimates. Both variables are normalized to have zero mean and standard deviation equal to 1 . Estimates obtained by two-stage least squares using an indicator for PSOE having the seats majority as an instrument for the indicator for PSOE being in power, while controlling for the winning margin in the 2007 municipal elections as defined in the text. Columns 1 and 2 use the full sample and third-degree polynomials in the winning margin, allowed to differ on either side of the threshold. Columns 3 and 4 restrict the sample to observations within the Calonico, Cattaneo and Titiunik (2014) optimal bandwidth around the threshold, with a linear control function of the winning margin with possibly different slopes on either side. All estimates are obtained by weighting each census area by the inverse of the number of sections in its municipality. Standard errors clustered at the municipal level.

baseline estimates are not driven by our particular choice of bandwidth but, instead, reflect the lack of any appreciable effect in data. Collectively, all results in this section lead us to conclude that there was no favouring of supporters in the allocation of Plan E projects. If distributive politics play a role inside cities, then this does not operate through the targeting of supporters' neighbourhoods.

Our results are robust to using alternative empirical strategies. For example, estimates from within-city regressions are discussed below. In other specifications, reported in a previous version of this paper (see Carozzi and Repetto 2017), we aggregated data and ran our RDD analysis at the municipal level. Reassuringly, these alternatives lead to the same null effects reported using our preferred RDD specification.

\subsection{Alternative Estimation Method}

Our main finding is that local politicians do not to target their supporters in the allocation of investments within cities. We now turn to a complementary estimation strategy leading to 
the same conclusions without relying on municipal close elections. To this end, we estimate the following model by OLS:

$$
I_{c m}=\alpha_{m}+\beta \text { VoteShareInc } \text { Im }_{p=1}+\sum_{p=1}^{P} \delta_{p} \text { VoteShare }_{p, c m}+\gamma_{2}^{\prime} X_{c m}+\epsilon_{c m}
$$

where $I_{c m}$ is some measure of investment in census area $c$ of municipality $m$ and VoteShareInc is the vote share of the incumbent's party, defined as the ruling party at the time of Plan E inception in late 2008. $\beta$ is the coefficient of interest. A positive $\beta$ implies that areas with relatively large support for the incumbent receive, on average, more investment. We also include a municipality fixed effect $\alpha_{m}$ to capture unobserved differences between municipalities. Additionally, we control for the vote shares of all the main parties - defined in section 2 - and our usual set of census area characteristics, $X_{c m}$, defined above. ${ }^{22}$

Given that we introduce the vote shares of all major parties as controls (among which there is always the incumbent's party), identification of $\beta$ comes from comparing how much voters of a given party are rewarded with investment when this party is in power relative to when it is not. Vote shares also serve as proxies for unobserved determinants of transfers that are correlated with the electoral preferences of voters. The identifying assumption, as usual, is that, conditional on all controls and municipal effects, the vote share of the incumbent is mean independent of the unobserved term $\epsilon_{c m}$.

In table B.4 in the appendix, we report estimates using three different measures of investment as dependent variables: a dummy for receiving at least one project, a variable that counts the number of projects received and, finally, the ratio of Plan E spending in a given census area over the municipal total. Results show that all coefficients are negative but very small in magnitude. A large increase in the vote share of the incumbent by 10 percentage points is associated with a relatively small decrease in the probability of receiving a project of 0.17 percentage points (see column 3). This coefficient is very small in magnitude and statistically insignificant. Similar results are found when using alternative measures of investment as dependent variables.

We interpret this as further evidence that local politicians do not target their supporters when deciding the spatial allocation of resources inside cities. One advantage of this alternative research strategy is that it does not rely exclusively on close election municipalities which will necessarily be more electorally competitive than the average. Additionally, it allows to use all the available information by including all electoral races and, hence, municipalities ruled by different parties.

\footnotetext{
${ }^{22}$ It is worth discussing briefly why we cannot use these measures of investment as dependent variables in our main RDD analysis. The RDD only provides exogenous variation in the identity of the mayor, not in the strength of its support in a given census area. Hence, an RDD analysis that uses $I_{c m}$ as a dependent variable would not be informative because finding a positive correlation between investment and having a PSOE mayor would not be evidence of the mayor favouring his voters.
} 


\section{Discussion}

As reported in the previous sections, we find that incumbents' supporters were not favoured in the allocation of Plan E projects within cities. In this section, we start by exploring the electoral consequences of investment projects. Specifically, we show that receiving investment projects is positively related to future voter turnout, suggesting that investment patterns could be used to promote the mobilization of voters. Then, we investigate the adequacy of our research design to study distributive politics and show that results are robust to several alternative specifications and additional analyses.

\subsection{Electoral consequences of receiving investment projects}

There is at least one margin through which voters respond to project allocations. Specifically, as panel A of table 5 shows, there is evidence that voters respond to projects in terms of an increase in turnout.

\section{TABLE 5}

THE EFFECT OF INVESTMENT ON TURNOUT AND NATIONAL ELECTION RESULTS

(1)

Turnout 2011

\section{A. Turnout Effects}

Project $1 / 0$

Inv. p.c.

Turnout 2007

Controls

$R^{2}$

Observations
$0.388^{* * *}$

$(0.07)$

$0.113^{* * *}$

$0.309^{* * *}$

$(0.02)$

FE + ctrls.

0.88

27880

$0.312^{* * *}$

$(0.02)$

$\mathrm{FE}+$ ctrls.

0.88

27544

PSOE share 2011

PSOE share 2011

B. National PSOE Vote Share

\begin{tabular}{lcc} 
Project $1 / 0$ & -0.038 & \\
Inv. p.c. & $(0.048)$ & -0.025 \\
& & $(0.018)$ \\
PSOE share 2008 & $0.729^{* * *}$ & $0.729^{* * *}$ \\
& $(0.016)$ & $(0.016)$ \\
\hline Controls & FE + ctrls. & FE + ctrls. \\
$R^{2}$ & 0.94 & 0.94 \\
Observations & 27823 & 27487
\end{tabular}

Notes: Census area level regressions including municipal fixed effects in all columns. Panel A reports estimates for the following OLS regression:

$$
\text { Turnout }_{c m}^{2011}=\beta I_{c m}+\text { Turnout }_{c m}^{2007}+\alpha_{m}+\gamma^{\prime} X_{c m}+\epsilon_{c m},
$$

where $c$ indexes census areas and $m$ municipalities. Turnout ${ }_{c m}^{2011}$ is the turnout in the 2011 municipal election in census area $m$, measured in percentage points. $I_{c m}$ is a measure of Plan $E$ investment which can be either a project dummy (column 1) or investment per capita (column 2), both measured at the census area level. The fixed effect $\alpha_{m}$ controls for municipal characteristics. The set of controls $X_{c m}$ is the same as the one used in equation 2 of section 4. In panel B, the outcome variable is, instead, the vote share of PSOE in the 2011 national election, and all specifications control for the previous (2008 elections') PSOE vote share. Standard errors clustered at the municipal level in all specifications. 
Results are obtained by estimating census-area level regressions of 2011 municipal election turnout on a measure of investment, 2007 turnout, municipal fixed effects, and the same set of controls used in our baseline specification. ${ }^{23}$ Investment is either measured as a project indicator, taking value 1 if a section received a Plan E project, or as total project cost per capita, measured at the census area level and standardized. For both investment measures we find a positive effect on turnout in response to Plan E investments. The coefficients are relatively small but strongly significant, with receiving a project being associated with an increase in turnout of almost 0.4 percentage points. Placebo estimates reported in figure B.7 in the appendix validate the empirical strategy pursued to obtain these estimates by showing that there is no effect of investment on previous municipal elections' turnout.

We interpret this result as suggesting that voters become more sensitive to the local level political agenda when observing the actual policies taking place. It is also evidence that projects have local electoral effects. Finally, they indicate there may be scope for the use of localized policies to mobilize voters.

\subsection{Other mechanisms and robustness checks}

A possible concern is that the investment plan carried out under Plan E is somehow illsuited to answer our research question. To start, the national government could have used the formal approval process to favour certain municipalities. As discussed in section 2, however, the vast majority of municipalities received the full amount they applied for (see also Montolio 2018; Tribunal de Cuentas 2013), suggesting that the approval process was, in fact, not imposing any substantial constraints or limitations on the choice of projects. One might still be concerned that the national-level PSOE government favoured aligned municipalities, either to benefit fellow party members or to directly gain votes at the local level. This could give the national government some ownership in the allocation process. In order to exclude this possibility, we modify our RDD analysis to study whether PSOE local governments received more total Plan E funding (in per capita terms). Reduced-form results (figure B.8 in the appendix) suggest that PSOE mayors were not granted any special treatment in the allocation of funds.

To show that our main estimates are not capturing partisan differences in preferences, we implement an RDD analysis using as dependent variable the fraction of projects belonging to each of the six most common categories (see table 1) and show that PSOE mayors tend to focus on the same types of projects as mayors from other parties (estimates are reported in table 6).

Another potential issue relates to the electoral returns of investment projects. Insofar as Plan $E$ was a national government initiative, its electoral effects may operate through changes in vote shares in national (rather than municipal) elections. If this were the case, then it would be unsurprising that we find no targeting of supporters, because municipalities would simply be unable to claim credit for the Plan E projects. However, census-area level regression results reported in table 5 show that areas receiving Plan $E$ investment do not experience an

\footnotetext{
${ }^{23}$ There are alternative estimation methods available. We can. for example, regress the change in turnout between 2011 and 2007 on investment and controls. This procedure is similar in spirit to the first difference estimator used in panel data, but unnecessarily imposes the restriction that the coefficient on the 2007 turnout equals 1 . We have also considered an alternative panel specification with census area fixed effects, which leads to analogous results.
} 
TABLE 6

NO DIFFERENCES IN THE CHOICE OF PROJECTS BY PARTY

\begin{tabular}{lcccccc}
\hline & Rehab. & Infrastr. & Soc./Cult. & Sports & Energy & Roads \\
\hline PSOE mayor & 0.025 & 0.079 & -0.092 & -0.038 & 0.031 & 0.030 \\
& $(0.069)$ & $(0.086)$ & $(0.070)$ & $(0.056)$ & $(0.049)$ & $(0.030)$ \\
\hline Mean & 0.19 & 0.15 & 0.19 & 0.11 & 0.10 & 0.01 \\
Bandwidth & 0.11 & 0.07 & 0.09 & 0.10 & 0.11 & 0.07 \\
Obs. & 1035 & 705 & 882 & 916 & 994 & 705 \\
\hline
\end{tabular}

Notes: RDD results at the municipal level. Estimates are obtained by two-stage least squares using an indicator for PSOE having the seats majority as an instrument for the indicator for PSOE being in power, while controlling for the winning margin in the 2007 municipal elections as defined in the text. In each column we use, as dependent variable, the fraction of projects of a given type carried out in the municipality, restricting the sample to observations within the Calonico, Cattaneo and Titiunik (2014)'s optimal bandwidth around the threshold, with a linear control function of the winning margin with possibly different slopes on either side. Robust standard errors in parentheses.

appreciable increase in the vote share of PSOE in the following national election. ${ }^{24}$ Receiving a project is associated with a decrease of 0.25-0.38 percentage points in the PSOE vote share in the following national elections. These estimates are very small, statistically insignificant at conventional levels, and are evidence against the existence of electoral returns accruing to the national government.

A potential challenge faced by our empirical strategy lies in that measuring who benefits directly from investment is difficult. In our analysis, we have implicitly assumed that that the benefits of receiving a Plan E project are limited to the census area that receives it, hence ruling out spillovers to neighbouring areas. However, it seems reasonable that at least some kinds of investments - such as gymnasiums, cultural centres, or sports facilities - provide services that are enjoyed by a larger constituency. ${ }^{25}$

To investigate this issue, we perform our analysis again by restricting our attention to types of projects for which benefits can be considered to be "strictly" localised, in the sense that these projects are more likely to benefit their immediate neighbours the most. To classify projects into this category, we use the descriptions included in the original Plan E data source. ${ }^{26}$ Secondly, we retain our initial catch-all definition of projects but we now allow benefits to extend to 100 metre radius circular buffers around the actual project locations. Hence, if a project falls within a specific census area A but less than 100 metres away from the boundary with another census area B we consider both A and B to benefit from this investment. Estimates for the bias measures created using the localised project benefits definition and the 100 metre buffers are

\footnotetext{
${ }^{24}$ Vote shares are in percentage points to facilitate the interpretation of the coefficients.

${ }^{25}$ Other investments, like a new sewage system, might even have negative externalities for the closest neighbours but benefiting the municipality as a whole.

${ }^{26}$ We specifically restrict our attention to i) rehabilitation of public space and ii) improvement in public spaces and road networks. Although this definition is somewhat arbitrary, some guidance on the selection of projects with localised benefits is offered by the literature on political budget cycles, which suggests that spending in parks and roads is very prone to strategic manipulation because of its visibility among voters (see for example Kneebone and McKenzie 2001; Drazen and Eslava 2010; and Repetto 2018).
} 
presented in the appendix in table B.6 (panels A and B, respectively). We continue to find small and insignificant coefficients. Most point estimates indicate the absolute value of the effects are less than $1 / 20$ of a standard deviation in the bias measure. ${ }^{27}$ We interpret these estimates as showing that our main result is robust to different assumptions about the reach of spatial benefits of local investment.

A complementary result shows further evidence of local benefits of Plan E investments. Table B.7 in the appendix reports results regressing, respectively, a project indicator and the total project cost per capita (in logarithms to facilitate interpretation) on the log of census area population. ${ }^{28}$ We find a strong and statistically significant correlation between population and allocation decisions, suggesting that local politicians are mindful of allocating projects to populated areas, presumably to maximize visibility and impact of these forms of spending.

Local politicians may lack the sophistication or the knowledge needed to use investment strategically. National-level politicians, who typically handle larger budgets and more professionalized bureaucracies, may be more experienced and skilled, and hence more aware of the possible benefits of engaging in distributive politics. While we cannot directly rule out this possibility, under the assumption that politicians are more sophisticated in larger municipalities, we can use a sample split to further investigate this hypothesis. Panels C and D of table B.6 replicate our RDD analysis splitting the sample between large and small municipalities, respectively. In order to preserve the significance of the first stage, we split the sample at the relatively low threshold of 3,000 inhabitants, which roughly corresponds to the first quartile of the municipal population distribution. Interestingly, the estimates remain small and indistinguishably different from zero both in large and in small municipalities. One could be concerned that our sample split fails to properly sort municipalities with respect to the sophistication of their local politicians. However, alternative empirical analyses using census-area regressions including the incumbent's vote share and focusing on province capitals only also lead to similar qualitative results. ${ }^{29}$

To ensure that our results are not exclusively driven by municipalities with little crosssectional variation in vote shares, we have also tried restricting the sample to i) municipalities with 3 or more census areas or ii) municipalities with a high variance in PSOE vote shares across their geography. In both cases point estimates are small in magnitude and not statistically significant.

A final note is due regarding different theories on the targets of distributive policies. Our hypothesis that politicians disproportionately target their supporters with investment is closely related to the core voters hypothesis in the political economy and political science literature (Cox and McCubbins, 1986). An alternative hypothesis poses that politicians should instead target swing voters, that is, voters with weak party preferences who may be willing to "switch sides" in response to economic favours (Lindbeck and Weibull, 1987; Dixit and Londregan, 1995).

\footnotetext{
${ }^{27}$ Alternative specifications using more lax definitions of localised benefits or narrower buffer sizes (such as 25 or 50 metres) yield analogous conclusions and are not reported for brevity.

${ }^{28}$ As before, we include the same controls used in the baseline specification and municipal fixed effects.

${ }^{29}$ The interested reader can refer to Table B.11 of the previous working paper version of this paper (Carozzi and Repetto 2017).
} 
However, it is generally difficult to identify swing voters from electoral data alone. ${ }^{30}$ While we show that local governments are not targeting their supporters, we cannot rule out that they target swing voters instead.

\section{Conclusions}

Local governments carry out a large share of public investment which, in turn, has longstanding effects on our cities and towns. In this paper we study whether the allocation of investment within cities is affected by the spatial distribution of voter support. Between 2009 and 2011, the Spanish government carried out a large scale stimulus program that transferred 12 billion Euros to municipalities to increase infrastructure spending and foster employment. This policy is well-suited to analyse how local politicians distribute resources inside municipalities.

We find that the spatial allocation of spending within municipalities is not directed to areas of strong electoral support for the incumbent. This result is robust to allowing investment to have a disperse spatial impact, to focusing only on those investment projects that are more likely to yield localised benefits, and to different ways of measuring supporter bias. We therefore conclude that previous evidence of tactical distribution of resources between levels of government does not carry over when translating the analysis to groups of voters within local areas. Complementary results show that areas receiving an investment project experience an increase in turnout, suggesting that spending might be a way to persuade voters to participate in local elections.

Our results contribute to the still very incomplete understanding of how electoral conditions and incentives shape the allocation of investments within the city. Despite the importance of local investment on national spending, the lack of data at a sufficiently disaggregated level has hampered the study of these issues. Our paper is a first step towards uncovering how distributive politics operate at the very local level. Several questions remain open, such as whether or not local politicians target swing voters within their jurisdictions. Further understanding of the determinants of local investment decisions remains an open topic for future research.

\footnotetext{
${ }^{30}$ For an exception in this regard, see Dahlberg and Johansson (2002).
} 


\section{References}

Ansolabehere, Stephen, and James M Snyder. 2006. "Party Control of State Government and the Distribution of Public Expenditures*." The Scandinavian fournal of Economics, 108(4): 547569 .

Baez, Javier Eduardo, Adriana Camacho, Emily Conover, and Román David Zárate. 2012. "Conditional cash transfers, political participation, and voting behavior." World Bank Policy Research Working Paper, , (6215).

Beland, Louis-Philippe. 2015. "Political parties and labor-market outcomes: Evidence from us states." American Economic fournal: Applied Economics, 7(4): 198-220.

Bracco, Emanuele, Ben Lockwood, Francesco Porcelli, and Michela Redoano. 2015. "Intergovernmental grants as signals and the alignment effect: Theory and evidence." fournal of Public Economics, 123: 78-91.

Brollo, Fernanda, and Tommaso Nannicini. 2012. “Tying your enemy's hands in close races: the politics of federal transfers in Brazil." American Political Science Review, 106(04): 742-761.

Calonico, Sebastian, Matias D Cattaneo, and Rocio Titiunik. 2014. "Robust Nonparametric Confidence Intervals for Regression-Discontinuity Designs." Econometrica, 82(6): 22952326.

Carozzi, Felipe, and Luca Repetto. 2017. "Distributive Politics Inside the City? The Political Economy of Spain's Plan E.” SERC-CEP Working Paper n. 212.

Case, Anne. 2001. "Election goals and income redistribution: Recent evidence from Albania." European Economic Review, 45(3): 405-423.

Cattaneo, Matias D, Michael Jansson, and Xinwei Ma. 2016. "rddensity: Manipulation testing based on density discontinuity." The Stata fournal (ii), 1-18.

Cox, Gary W. 2009. "Swing voters, core voters, and distributive politics." Political Representation, 342-356.

Cox, Gary W, and Mathew D McCubbins. 1986. "Electoral politics as a redistributive game." fournal of Politics, 48(2): 370-389.

Curto-Grau, Marta, Albert Solé-Ollé, and Pilar Sorribas-Navarro. 2018. "Does Electoral Competition Curb Party Favoritism?” American Economic fournal: Applied Economics.

Dahlberg, Matz, and Eva Johansson. 2002. "On the Vote-Purchasing Behavior of Incumbent Governments." The American Political Science Review, 96(2): 27-40.

Dixit, Avinash, and John Londregan. 1995. "Redistributive Politics and Economic Efficiency." The American Political Science Review, 89(4): 856-866. 
Drazen, Allan, and Marcela Eslava. 2010. "Electoral manipulation via voter-friendly spending: Theory and evidence." fournal of development economics, 92(1): 39-52.

Ferreira, Fernando, and Joseph Gyourko. 2009. "Do Political Parties Matter? Evidence from US Cities*." The Quarterly journal of economics, 124(1): 399-422.

Fiva, Jon H, Olle Folke, and Rune J Sørensen. 2018. "The power of parties: evidence from close municipal elections in Norway." The Scandinavian fournal of Economics, 120(1): 3-30.

Folke, Olle. 2014. "Shades of brown and green: party effects in proportional election systems." fournal of the European Economic Association, 12(5): 1361-1395.

Gelman, Andrew, and Guido Imbens. 2014. "Why high-order polynomials should not be used in regression discontinuity designs.” National Bureau of Economic Research.

Golden, Miriam, and Brian Min. 2013. "Distributive politics around the world." Annual Review of Political Science, 16: 73-99.

Imbens, Guido W., and Thomas Lemieux. 2008. "Regression discontinuity designs: A guide to practice." fournal of Econometrics, 142(2): 615-635.

Kneebone, Ronald D, and Kenneth J McKenzie. 2001. "Electoral and partisan cycles in fiscal policy: An examination of Canadian provinces." International Tax and Public Finance, 8(56): $753-774$.

Lee, David S. 2008. "Randomized experiments from non-random selection in U.S. House elections." Journal of Econometrics, 142(2): 675-697.

Levitt, Steven D., and James M. Snyder, Jr. 1995. "Political Parties and the Distribution of Federal Outlays." American fournal of Political Science, 39(4): 958-980.

Lindbeck, Assar, and Jörgen W Weibull. 1987. "Balanced-budget redistribution as the outcome of political competition." Public choice, 52(3): 273-297.

Manacorda, Marco, Edward Miguel, and Andrea Vigorito. 2011. "Government transfers and political support." American Economic fournal: Applied Economics, 3(3): 1-28.

McCrary, Justin. 2008. "Manipulation of the running variable in the regression discontinuity design: A density test.” Journal of Econometrics, 142(2): 698-714.

Migueis, Marco. 2013. "The effect of political alignment on transfers to Portuguese municipalities." Economics \& Politics, 25(1): 110-133.

Montolio, Daniel. 2018. "The effects of local infrastructure investment on crime." Labour Economics.

OECD. 2013. Investing Together: Working Effectively across Levels of Government. OECD publishing. 
Pettersson-Lidbom, Per. 2008. "Do parties matter for economic outcomes? A regressiondiscontinuity approach." Journal of the European Economic Association, 6(5): 1037-1056.

Pop-Eleches, Cristian, and Grigore Pop-Eleches. 2012. "Targeted government spending and political preferences." Quarterly Journal of Political Science, 7(3): 285-320.

Repetto, Luca. 2018. "Political budget cycles with informed voters: evidence from Italy." The Economic fournal.

Solé-Ollé, Albert, and Elisabet Viladecans-Marsal. 2013. "Do political parties matter for local land use policies?” fournal of Urban Economics, 78: 42-56.

Solé-Ollé, Albert, and Pilar Sorribas-Navarro. 2008. "The effects of partisan alignment on the allocation of intergovernmental transfers. Differences-in-differences estimates for Spain." Journal of Public Economics, 92(12): 2302-2319.

Strömberg, David. 2004. "Radio's impact on public spending." The Quarterly Journal of Economics, 189-221.

Tribunal de Cuentas. 2013. "Informe de fiscalizacion del Fondo Estatal de Inversion Local." n. $982 / 2013$.

Trounstine, Jessica. 2006. "Dominant regimes and the demise of urban democracy." fournal of Politics, 68(4): 879-893.

Voigtlaender, Nico, and Hans-Joachim Voth. 2014. "Highway to Hitler." NBER Working Paper series 20150.

Weingast, Barry R, Kenneth A Shepsle, and Christopher Johnsen. 1981. "The Political Economy of Benefits and Costs: A Neoclassical Approach to Distributive Politics." fournal of Political Economy, 89(4): 642-64.

Wright, Gavin. 1974. "The Political Economy of New Deal Spending: An Econometric Analysis." The Review of Economics and Statistics, 56(1): 30-38. 


\section{Appendix}

\section{Appendix A. Data sources}

\section{Municipality codes and names; population}

To have a reliable list of municipality names and official municipality and province codes, we use the INE list of all Spanish municipalities for the years 2001-2011.

URL: http://www.ine.es/daco/daco42/codmun/codmun11/11codmunmapa.htm

Population data at the municipal level is available from 1996 onwards at the Padrón continuo municipal de habitantes:

URL: http://www.ine.es/dynt3/inebase/es/index.html?padre $=517 \& \mathrm{dh}=1$

\section{Census area maps (shapefiles)}

To be able to connect electoral data (available at the census area level) and the investment projects (geolocated with latitude and longitude), we need shapefiles with the borders of each census area. Since boundaries usually change over time, we need to have updated maps for each municipal election year (2007 and 2011) before and after the Plan E investment program. The 2011 shapefile with all census areas is freely available at the following url:

URL: http://www.ine.es/censos2011_datos/cen11_datos_resultados_seccen.htm

We also purchased the map for 2007 directly from INE, which we use as a reference in all the empirical analysis. In order to be able to assign the data from the 2001 Census to the 2007 census areas, we also bought the shapefile map for 2001 from the same source.

\section{Plan E Investment data}

The Plan E data on investment projects with geographical coordinates and amount were downloaded by hand from:

URL: http://www.seap.minhap.gob.es/fondosinversionlocal/utilidades/geolocalizacion-deproyectos.html

and saved as a .csv directly. Each investment project comes with, among other variables, the geographical coordinates. Those coordinates are then used, together with the 2007 shapefile, in ArcGIS to overlay the investment project data (as a "point layer") with the census area polygons as described below.

\section{Electoral data}

The electoral data are at the "Mesa" level (= polling stations, within-municipality) for several municipal and national elections. Data are then aggregated at the census area level in order to have the same level of aggregation of the shapefiles and the Census data. Each census area usually contains just a handful of polling stations, so the amount of aggregation is minimal.

URL: http://www.infoelectoral.interior.es/min/areaDescarga.html?method=search

There, we downloaded electoral results for the 1999, 2003, 2007 and 2011 municipal election, plus the 2000, 2004 and 2008 national elections, both at the disaggregated "mesa" level and at the municipal level.

Those data lack information on the identity of the mayor in each year and on the corresponding party in power, so we obtain such information using data from 
URL: http://www.seap.minhap.gob.es/en/web/areas/politica_local/sistema_de_informacion_local_SIL-/datos_legislaturas_1979_2015.html

Census area data We downloaded some variables, used as controls in the empirical analysis, from the 2001 Population census directly from the INE website:

URL: http://www.ine.es/censo/es/inicio.jsp

We obtain population data at the census area level for 2007 and 2011 from:

URL: http://www.ine.es/jaxi/menu.do?type=pcaxis\&path=/t20/e245/\&file=inebase \&L=0

Finally, we obtain information from Corine Land cover on the fraction of urban discontinuous terrain from:

URL: http://www.eea.europa.eu/data-and-maps/data/clc-2006-vector-data-version-6

\section{Data restrictions}

Our final dataset is based on the 2007 census areas for which we have information on the geographical boundaries (and coordinates). These areas are those that appear in the 2007 shapefile from INE. Of the 35,323 census areas in this dataset, we drop 5,833 belonging to municipalities with only one census area. Then, we drop municipalities where the mayor does not belong to any of the 9 largest parties, as defined in section 3 in the main text. By doing this, we lose 1,405 additional areas. Finally, we drop the municipality of "Mañón", because there is a conflict between the map - which has it divided in two census areas - and the electoral data, where it appears as having just one.

Regarding the projects data, the original data has 57,850 of them but 15,682 of them are incorrectly geo-located. We drop 6,574 projects that have no localised benefits, such as those related to modernization of the electronic equipment of municipal buildings or to sewage works. With the help of a research assistant, we went through all the remaining projects with incorrect geo-coding and we were able to hand-code roughly one-fifth of them. ArcGIS is used to assign all the 38,353 correctly geo-localised projects (which are points with geographical coordinates) to census areas (areas with polygon boundaries).

After this step, we have a dataset at the census area level. We replace all the Plan E variables (such as the dummy for receiving at least one project) with zeros if a given census area did not receive any project. In the special case in which we observe, in our sample, that the whole municipality carried out no investment projects at all, we replace all variables as missing instead. This is the case for only 28 municipalities. Given that the cost per capita variable has some large outliers, we replace as missing all observations in the top $1 \%$ of the cost per capita distribution when constructing our extensive bias measure.

\section{Construction of the final dataset}

The basis of our dataset are the 35,323 census areas in which Spain was divided as of 2007, as they appear in the INE shapefile. To assign investment projects - which come with latitude and longitude - to census areas we need information on the exact boundaries of each area, obtained from a shapefile for all 2007 census areas. Using ArcGIS 10.3.1, we overlay the point layer (that is, the dataset of geolocated project points) to the map of census areas. ArcGIS then 
calculates how many project points fall into each census areas, and the total cost. Finally, it saves the resulting dataset as a comma-separated values file that can be read by STATA.

The electoral data for 2007 are then directly merged using a unique census area identifier (labelled CUSEC in the raw data) to the main dataset. A slight complication arises when one tries to merge information for other years (such as, for instance, the 2001 Population Census data or electoral data for other years) to the 2007 census area dataset, because the boundaries of the census areas change over time. To be able to merge data from other years with the 2007 dataset, we create, for each year in which a map shapefile is available (2001 and 2011), a dataset that links the census areas boundaries to the 2007 ones. These two datasets allow us to directly link data for 2001 and 2011 to the 2007 census areas.

As an illustration on how census areas are linked across different years, consider the case in which the 2001 census area $A$ is divided in two areas in $2007, B$ with surface $9 / 10$ of the original one, and $C$ with surface 1/10. Imagine that we want to have the variable "number of foreigners", only available for 2001, for all the 2007 census areas. Assume, for the sake of the example, that the number of foreigners living in area $A$ was 100 in 2001. To assign this number to the new 2007 boundaries, we simply assume that those people are uniformly located in space. Hence, we assign 90 of them to area $B$ and the remaining 10 to area $C .{ }^{31}$ This simple procedure allows us to obtain a single cross-section for the 2007 census areas with several variables from other years, with the advantage of having kept the geographical boundaries fixed.

\footnotetext{
${ }^{31}$ For the years in which no shapefile is available, we first merge to the closest year available and then apply the described procedure.
} 


\section{Appendix B. Additional results}

This appendix includes a set of descriptives and complementary results - in the forms of figures, tables and images - which we are referred to in the paper. Table B.1 shows descriptive statistics at the municipal level.

TABLE B. 1

DESCRIPTIVE STATISTICS - MUNICIPAL LEVEL

\begin{tabular}{lcccc}
\hline & Mean & Std. dev. & Min & Max \\
PSOE mayor & 0.50 & 0.50 & 0.000 & 1.000 \\
PP mayor & 0.33 & 0.47 & 0.000 & 1.000 \\
N. of census areas & 13.72 & 70.29 & 2.000 & 2381.000 \\
Seats in the municipal council & 14.25 & 4.74 & 9.000 & 57.000 \\
Plan E spending, per capita & 207.05 & 71.42 & 0.000 & 303.681 \\
Unemployment in 2007 & 0.07 & 0.03 & 0.012 & 0.228 \\
Unemployment in 2008 & 0.10 & 0.03 & 0.020 & 0.280 \\
Unemployment in 2009 & 0.12 & 0.04 & 0.017 & 0.309 \\
Unemployment in 2010 & 0.12 & 0.04 & 0.022 & 0.332 \\
Unemployment in 2011 & 0.14 & 0.05 & 0.027 & 0.349 \\
Population & 19,527 & 89852 & 1099 & 3132463 \\
Observations & 2046 & & & \\
\hline
\end{tabular}

Notes: Averages for some municipal-level characteristics of interest for the 2,046 municipalities in the sample. Electoral figures refer to the 2007 municipal election. Due to lack of municipal information on active population at the municipal level, unemployment is calculated as number of registered unemployed divided by the population aged 15-65.

TABLE B.2

Descriptives Statistics for Investment Projects

\begin{tabular}{lcccc}
\hline & All & FEIL & FEESL & CN \\
\hline A. All projects & & & & \\
Cost in million euros & 12308 & 7933 & 4232 & 143 \\
Participating municipalities & 8097 & 8058 & 8067 & 713 \\
Average cost of a project (thousand EUR) & 213 & 260 & 168 & 69 \\
N. of projects & 57850 & 30566 & 25214 & 2070 \\
& & & & \\
\hline B. Only correctly geocoded projects & & & & \\
Cost in million euros & 9376 & 6270 & 3106 & \\
Participating municipalities & 7210 & 6879 & 8023 & \\
Average cost of a project (thousand EUR) & 244 & 292 & 184 & \\
N. of projects & 38353 & 21460 & 16893 & \\
\hline
\end{tabular}

Notes: Descriptive statistics for investment projects. Panel A uses the universe of Plan E projects and Panel B restricts attention to projects with correct geo-location in our sample.

Table B. 2 presents descriptives for all projects and projects in our sample, respectively. The difference between the two samples corresponds to projects for which geo-coding is not available and projects which we exclude because they clearly yield no geographically precise effect 
on voters (for instance, improvements to the city hall internet connection, etc.). In our sample we also drop all projects of the $C N$ investment program, because it was a plan meant to distribute resources to provincial rather than municipal authorities. Likewise, we exclude projects executed by associations of municipalities as we cannot attribute a single incumbent party to these associations. We have a total of 38,353 correctly geocoded projects roughly equally divided between the two Plan E programs (FEIL and FEESL). Our sample of correctly geocoded projects covers 7,210 municipalities (90\% of the total). The average project costs 244 thousand Euros, with projects being more costly in FEIL than FEESL. Comparing panels A and B of Table B. 2 we can note that projects that are not in our sample are slightly cheaper on average.

Table B.3 presents first-stage estimates corresponding to equation 1. In the first two columns we use the whole sample and include in estimation a third-degree polynomial in the winning margin, while in the last two we restrict the sample to observations within the Calonico, Cattaneo and Titiunik (2014) optimal bandwidth and use a linear control function. Each observation is weighted by the inverse of the number of census areas in the municipality so that all municipalities have the same weight. Columns 2 and 4 also include the set of controls outlined in section 4 . We observe in all columns that when PSOE wins a seat majority by a narrow margin there is a $30-38 \%$ increase in the probability of having a PSOE mayor. Note that this jump is similar to the one observed in figure 3 in the paper.

\section{TABLE B.3}

First-STAGE Regressions

\begin{tabular}{lccccc}
\hline & \multicolumn{2}{c}{ Full sample } & & \multicolumn{2}{c}{ CCT bandwidth } \\
\cline { 2 - 3 } \cline { 5 - 6 } PSOE seats majority & $0.312^{* * *}$ & $0.307^{* * *}$ & & $0.380^{* * *}$ & $0.372^{* * *}$ \\
& $(0.052)$ & $(0.052)$ & & $(0.053)$ & $(0.053)$ \\
\hline Controls & $\mathrm{N}$ & $\mathrm{Y}$ & $\mathrm{N}$ & $\mathrm{Y}$ \\
F-statistic & 36.11 & 35.15 & & 50.90 & 49.42 \\
Obs. & 28043 & 28031 & & 13315 & 13314 \\
\hline
\end{tabular}

Notes: The dependent variable is an indicator taking value 1 if a municipality has a PSOE mayor. Main independent variable of interest is a dummy taking value 1 if the $P S O E$ winning margin is positive. All specifications control for the vote share distance to PSOE seat majority in the 2007 municipal elections. Columns 1 and 2 use the full sample and third degree polynomials, allowed to differ at either side of the threshold. Columns 3 and 4 restrict the sample to a bandwidth around the threshold estimated as in Calonico, Cattaneo and Titiunik (2014) and includes a linear control function in the winning margin, with slope allowed to differ on either side of the threshold.

Table B.4 provides OLS estimates of the effect of the mayor's vote share on different measures of investments ( $\beta$ in equation 3 in the text). The investment measures are i) a dummy taking value 1 if the census area received a Plan E project, ii) the number of Plan E projects received by a census area, and iii) the fraction of total resources to the municipality allocated in a census area. The effect of mayoral support on investment is estimated using OLS with municipal fixed effects.

In table B.6, we report results for several robustness checks discussed in section 5 .

Figure B.7 presents placebo estimates from the same turnout regression estimated in table 5, reporting the baseline result for 2011 turnout as reference and using, as dependent variable, turnout levels from before the onset of Plan E. To take into account census-area unobservable 
TABLE B.4

Alternative Estimation Strategy

(1)

(2)

(3)

\begin{tabular}{lccc} 
& Project $1 / 0$ & Project $1 / 0$ & Project $1 / 0$ \\
\hline Vote Share Inc. (2007) & -0.039 & -0.024 & -0.017 \\
& $(0.03)$ & $(0.03)$ & $(0.03)$ \\
\hline Controls & FE + geo ctrls. & FE+ elect. ctrls. & FE+ full ctrls. \\
$R^{2}$ & 0.33 & 0.28 & 0.33 \\
Observations & 27892 & 27903 & 27892
\end{tabular}

\begin{tabular}{lccc}
\hline & N. projects & N. projects & N. projects \\
\hline Vote Share Inc. (2007) & -0.159 & -0.059 & -0.067 \\
& $(0.14)$ & $(0.12)$ & $(0.13)$ \\
\hline Controls & FE + geo ctrls. & FE+ elect. ctrls. & FE+ full ctrls. \\
$R^{2}$ & 0.38 & 0.34 & 0.38 \\
Observations & 27892 & 27903 & 27892 \\
& & & \\
\hline & Inv. share & Inv. share & Inv. share \\
\hline Vote Share Inc. (2007) & -0.006 & -0.006 & -0.003 \\
& $(0.01)$ & $(0.01)$ & $(0.01)$ \\
\hline Controls & FE + geo ctrls. & FE+ elect. ctrls. & FE+ full ctrls. \\
$R^{2}$ & 0.45 & 0.44 & 0.45 \\
Observations & 27892 & 27903 & 27892 \\
\hline
\end{tabular}

Notes: Census-area level regressions including municipal fixed effects in all specifications. Dependent variables are measures of census-area level investments in all specifications. The first row uses a project dummy (taking value 1 if the census area received a project), the second row uses the number of projects received by the census area, and the third row uses the fraction of all municipal Plan E spending allocated to that census area. Standard errors clustered at the municipal level.

characteristics, we control for lagged turnout in each specification (except in the 1999 regression, where we have no data on the previous election results). As expected, regressing pre-Plan $E$ turnout on investment shows no statistically significant correlation except in one case where we find a relatively small and negative effect. Overall, estimates are much smaller in absolute value than the baseline 2011 effect, mitigating concerns that Plan E investment is correlated with other, unobserved, census-area level counfounders than could bias our results.

Results reported in table B.7 indicate that more populated areas within a municipality receive more projects. To show this, we estimate census area level regressions of measures of investment (a project dummy and log total investment, respectively) on a municipal fixed effect, the log of population and our set of controls. The table reports the log population coefficients. For both investment measures we find strong and significant effects of population on the probability of receiving a project (column 1) and on total investment (column 2). Column 1 indicates that areas with $1 \%$ larger populations have $0.18 \%$ more probability of receiving a project. The estimate in column 2, obtained using only census areas receiving projects, show 
TABLE B.5

Alternative Estimation Strategy - Alignment Heterogeneity

\begin{tabular}{lccc}
\hline & Project 1/0 & N. projects & Inv. share \\
A. Alignment Interaction & & & \\
Vote Share Inc. (2007) & 0.032 & -0.070 & -0.007 \\
& $(0.08)$ & $(0.23)$ & $(0.02)$ \\
Vote Share Inc. $\times$ Aligned & -0.114 & 0.007 & 0.010 \\
& $(0.17)$ & $(0.50)$ & $(0.06)$ \\
\hline Observations & 27892 & 27892 & 27892 \\
\hline & Project $1 / 0$ & N. projects & Inv. share \\
B. Unaligned Municipalities & & & -0.017 \\
Vote Share Inc. (2007) & 0.000 & -0.153 & $(0.03)$ \\
& $(0.08)$ & $(0.23)$ & 14131 \\
\hline Observations & 14131 & 14131 & FE+ full ctrls \\
Controls & FE+ full ctrls & FE+ full ctrls & \\
\hline
\end{tabular}

Notes: Census-area level regressions including municipal fixed effects in all specifications. Dependent variables are measures of census-area level investments in all specifications. In the first column, we use a project dummy (taking value 1 if the census area received a project); in the second column we use the number of projects received by the census area; and in the third column we use the fraction of all municipal Plan E spending allocated to that census area. Standard errors clustered at the municipal level.

that a $1 \%$ increase in population is associated with $0.33 \%$ more spending.

Finally, figure B.8 displays a reduced-form RDD plot using municipal Plan E funds per capita as our outcome variable. We can observe from the graph that there is no discontinuity in the amount of received Plan E funds when comparing municipalities where PSOE narrowly lost a majority with municipalities where PSOE narrowly won. We only report this reduced form graph for ease of exposition but fuzzy-RD estimates adjusting for the jump in the first stage also lead to very small and insignificant coefficients. 


\section{Figure B.7}

\section{Turnout Baseline Effect and Placebos}

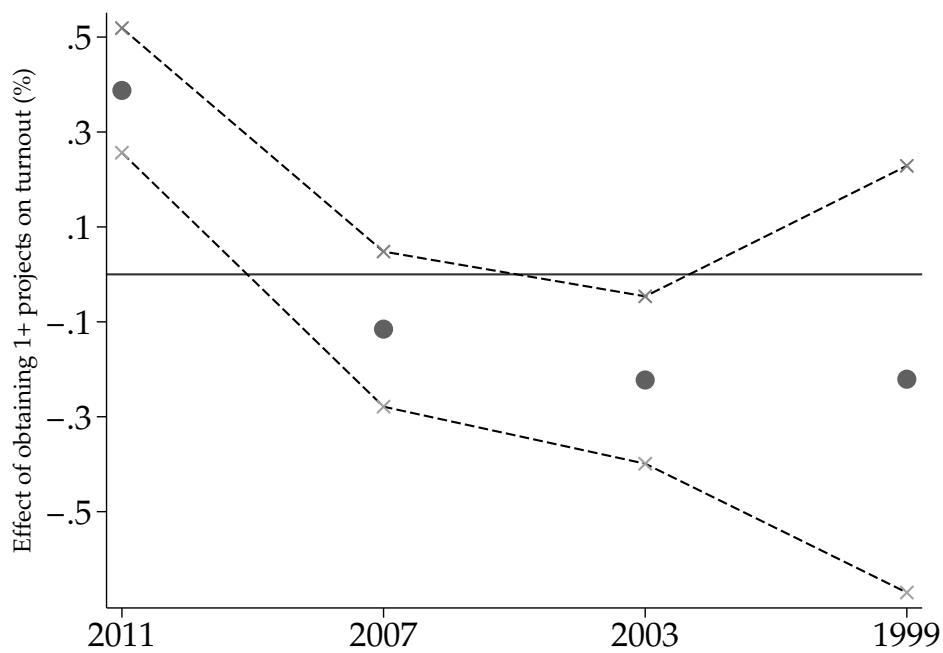

Notes: Regression estimates from the specification used in table 5 and corresponding confidence intervals. The dependent variable, turnout in the different municipal elections, is regressed on a project dummy, a set of controls (including lagged turnout) and a municipal level fixed effect. Standard errors used to create confidence intervals are clustered at the municipal level.

\section{FIGURE B.8 \\ No Difference in Plan E TAKe-up}

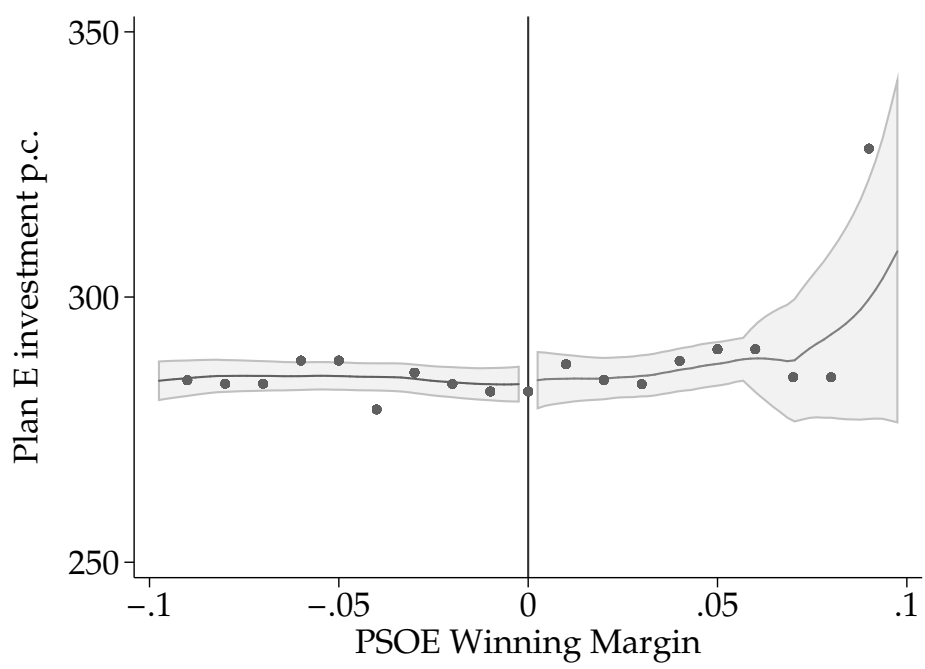

Notes: The vertical axis measures the amount of Plan E funding per capita received by a municipality. Horizontal axis measures PSOE Winning Margin calculated following the method outlined in section 4.1. Dots represent averages within $1 \%$ bins of the winning margin. The lines are local linear regression estimates obtained using an Epanechnikov kernel with bandwidth calculated using Silverman's rule-of-thumb. 
TABLE B.6

RDD Additional Results

\begin{tabular}{|c|c|c|c|c|}
\hline & \multicolumn{2}{|c|}{ Extensive Margin } & \multicolumn{2}{|c|}{ Intensive Margin } \\
\hline & $(1)$ & (2) & (3) & $(4)$ \\
\hline \multicolumn{5}{|c|}{ A. Projects with Localized Benefits } \\
\hline PSOE mayor & $\begin{array}{c}0.049 \\
(0.200)\end{array}$ & $\begin{array}{c}0.015 \\
(0.155)\end{array}$ & $\begin{array}{l}-0.142 \\
(0.087)\end{array}$ & $\begin{array}{l}-0.095 \\
(0.076)\end{array}$ \\
\hline F-Stat & 35.2 & 49.4 & 35.2 & 39.8 \\
\hline Bandwidth & 0.50 & 0.10 & 0.50 & 0.08 \\
\hline Obs. & 27885 & 13245 & 27517 & 12048 \\
\hline \multicolumn{5}{|c|}{ B. 100 Metre Buffers } \\
\hline PSOE mayor & $\begin{array}{c}-0.048 \\
(0.181)\end{array}$ & $\begin{array}{l}-0.041 \\
(0.129)\end{array}$ & $\begin{array}{c}0.038 \\
(0.056)\end{array}$ & $\begin{array}{l}-0.008 \\
(0.039)\end{array}$ \\
\hline F-Stat & 35.2 & 55.8 & 35.2 & 49.4 \\
\hline Bandwidth & 0.50 & 0.11 & 0.50 & 0.10 \\
\hline Obs. & 27885 & 14687 & 27522 & 13079 \\
\hline \multicolumn{5}{|c|}{ C. Large Municipalities } \\
\hline PSOE mayor & $\begin{array}{c}0.006 \\
(0.314)\end{array}$ & $\begin{array}{c}0.008 \\
(0.246)\end{array}$ & $\begin{array}{l}-0.053 \\
(0.168)\end{array}$ & $\begin{array}{l}-0.086 \\
(0.149)\end{array}$ \\
\hline F-Stat & 10.0 & 14.9 & 10.0 & 11.5 \\
\hline Bandwidth & 0.50 & 0.09 & 0.50 & 0.08 \\
\hline Obs. & 26927 & 12166 & 26559 & 10923 \\
\hline \multicolumn{5}{|c|}{ D. Small Municipalities } \\
\hline PSOE mayor & $\begin{array}{c}0.141 \\
(0.262)\end{array}$ & $\begin{array}{c}0.032 \\
(0.236)\end{array}$ & $\begin{array}{l}-0.149 \\
(0.102)\end{array}$ & $\begin{array}{l}-0.147 \\
(0.096)\end{array}$ \\
\hline F-Stat & 63.8 & 70.0 & 63.8 & 67.4 \\
\hline Bandwidth & 0.50 & 0.12 & 0.50 & 0.11 \\
\hline Obs. & 958 & 492 & 958 & 459 \\
\hline
\end{tabular}

Notes: RDD results for the extensive and intensive margin measures of PSOE supporter bias. Both variables are normalized to have zero mean and standard deviation equal to 1. RDD estimates are obtained by two-stage least squares using an indicator for PSOE having the seats majority as an instrument for the indicator for PSOE being in power, while controlling for the winning margin in the 2007 municipal elections as defined in the text. Columns 1 and 2 use the full sample and third-degree polynomials in the winning margin, allowed to differ on either side of the threshold. Columns 3 and 4 restrict the sample to observations within the Calonico, Cattaneo and Titiunik (2014)'s optimal bandwidth around the threshold, with a linear control function of the winning margin with possibly different slopes on either side. Panel A uses only project types considered to have strongly localised geographical benefits (see text). Panel B uses, as outcome variables, measures obtained assuming that investment projects affect census areas within 100 metres of the geo-coded location. Panel C and D restrict the sample to municipalities larger or smaller than 3,000 inhabitants (respectively). First-stage F-statistics and bandwidth around the threshold are indicated alongside observations in the table foot. All estimates are obtained by weighting each census area by the inverse of the number of sections in its municipality. Standard errors clustered at the municipal level. 
TABLE B.7

Project Allocation \& Census Area Population

\begin{tabular}{lcc}
\hline & Project $1 / 0$ & $\log ($ Investment $)$ \\
\hline Log population (2007) & $0.185^{* * *}$ & $0.334^{* * *}$ \\
& $(0.014)$ & $(0.049)$ \\
\hline Controls & FE + ctrls. & FE + ctrls. \\
$R^{2}$ & 0.33 & 0.26 \\
Observations & 27925 & 11268 \\
\hline
\end{tabular}

Notes: Census area level regressions including municipal fixed effects in all specifications. In column 1 the dependent variable is a dummy taking value 1 if the census area received a Plan E project. In column 2 the dependent variable is the log of the total investment received, excluding census areas receiving no projects. Both columns include the set of controls described in section 4. Standard errors clustered at the municipal level. 


\section{Figure B.9}

\section{EXAMPles of Plan E InVEstments}

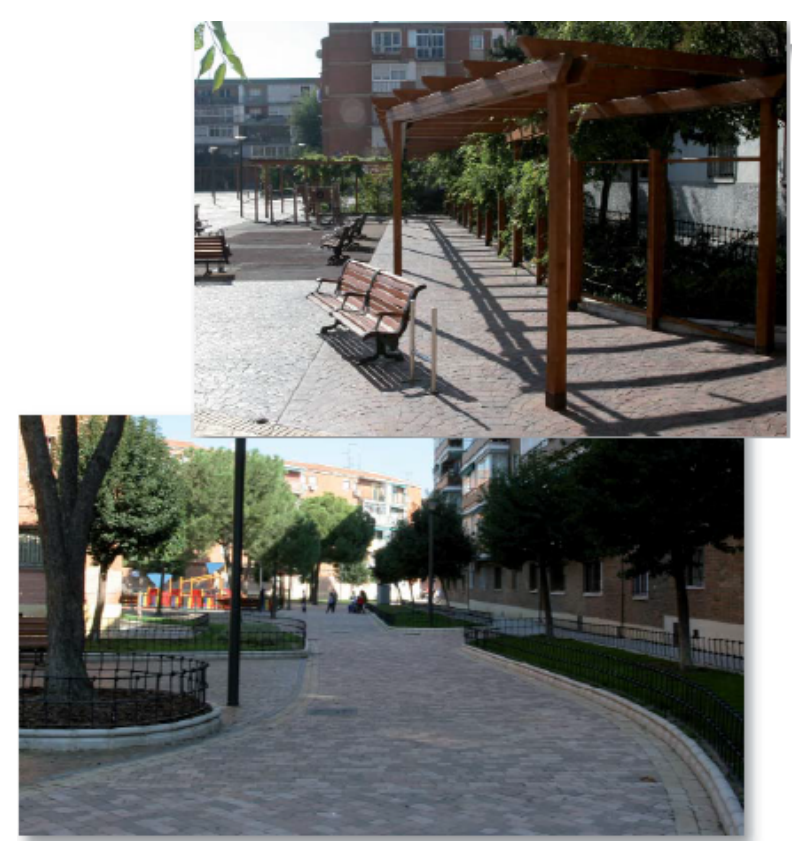

Restoration and accessibility improvement in nearby streets in the urban spaces around Eresma, Toro and Tormes streets in the municipality of Leganés, south of Madrid. The total cost of this project was $€ 3,200,000$, financed by Plan $E$ through FEIL.

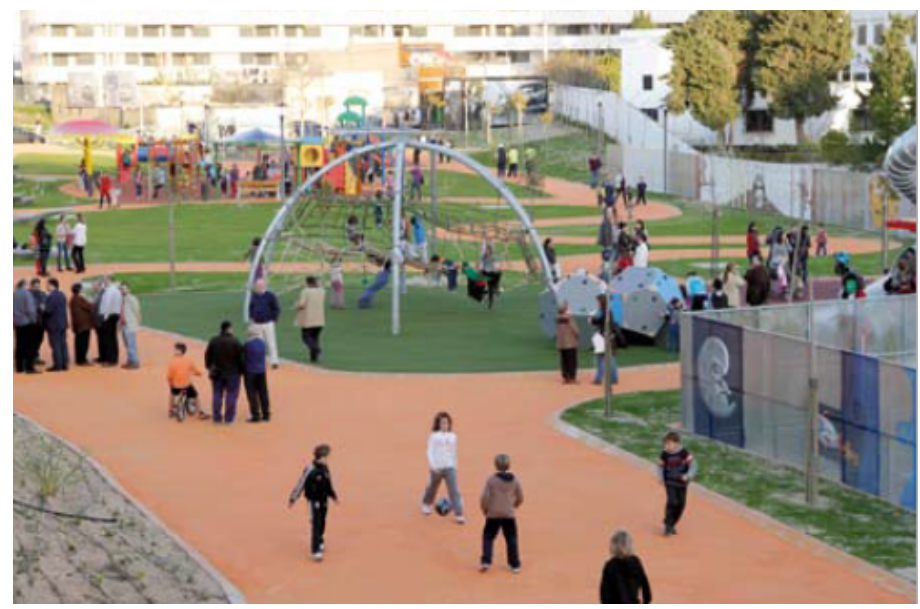

Environmental adaptation and improvement in the low areas of Barrio del Villablanca, in the municipality of Almería, in Southern Spain. The total cost of this project was $€ 4,864,380$ financed by Plan $E$ through FEESL. 
Figure B.10

Plan E Signboard template

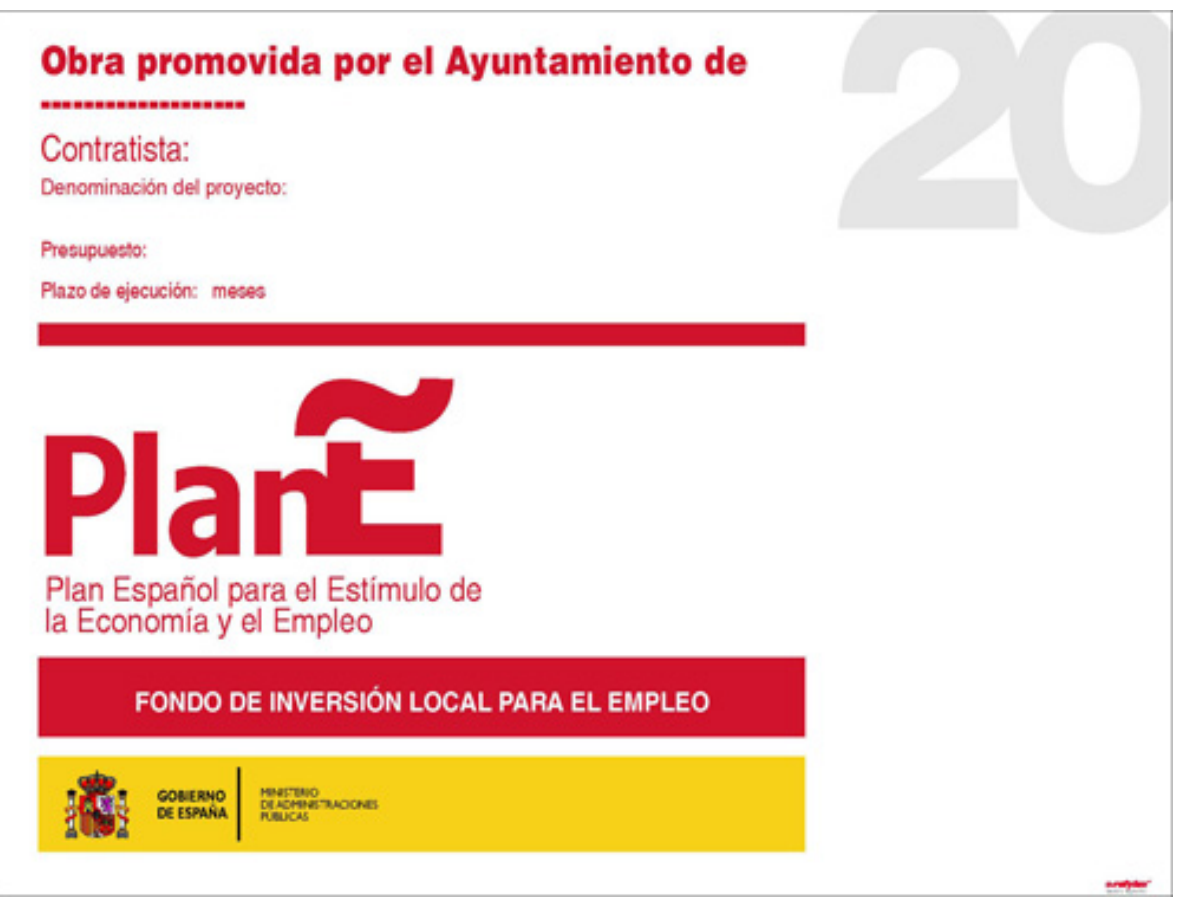

Notes: Signboard template for Plan E projects. From top to bottom, the signboard must contain: name of the municipality, the contractor, and the project; the amount spent and the expected completion time; a Plan E logo; the government logo. 